\title{
THE DISTRIBUTION OF THE ABO BLOOD GROUPS IN JAPAN ${ }^{1}$
}

\author{
Yoshiko Fujita, Masako Tanimura, and Katumi Tanaka \\ Department of Human Genetics, Tokyo Medical and Dental University, Tokyo
}

\begin{abstract}
Summary Data on ABO blood groups of 4,464,349 Japanese individuals were collected from prefectural health departments, health centers, and Red Cross blood centers in the whole country. Phenotypic and gene frequencies for each subpopulation were calculated and tabulated.

Phenotypic frequencies in the whole sample are $29.25 \% \mathrm{O}, 38.65 \% \mathrm{~A}$, $22.15 \% \mathrm{~B}$ and $9.95 \% \mathrm{AB}$. Gene frequencies are estimated to be $\mathrm{p}\left(I^{\mathrm{A}}\right)=$ $0.2833, \mathrm{q}\left(I^{\mathrm{B}}\right)=0.1759$, and $\mathrm{r}\left(I^{\mathrm{O}}\right)=0.5407$.

Significant gradients of the gene frequencies were apparent, i.e. the $I^{\mathrm{A}}$ gene is increased and $I^{\mathrm{B}}$ and $I^{\mathrm{O}}$ genes are decreased from the northeast to the southwest.

There are a slight, but significant, decrease in group $O$ and increases in other groups in recent years. Possible causes of these changes were discussed.
\end{abstract}

\section{INTRODUCTION}

Country-wide distribution of ABO blood groups in Japan was studied first by Furuhata (1933) on more than four hundreds thousands individuals. In 1940, Kobayasi cited ABO data on 530 thousands Japanese individuals from 261 references published during the period from 1922 to 1939 and tabulated frequencies of the phenotypes and alleles in all of 47 prefectures. Similar studies were carried out by Tanaka (1959), Nei and Imaizumi (1966), and Akaishi and Kudo (1975), compiling so far accessible data. These studies except Furuhata's one (1933) were based upon numerous sources obtained during periods as long as 18 to 50 years or more.

Recently extensive data on ABO blood groups became available at health centers, Red Cross blood centers, and prefectural health departments in the whole country. These data were collected, analyzed and presented in this communication.

Received November 22, 1977

1 This study was supported by the Scientific Research Grant from the Ministry of Education, Science, and Culture No. 037020 in 1975 and No. 137071 in 1976 and 1977. 


\section{MATERIALS AND METHODS}

In September 1973, a letter was sent addressed to the health department of each prefecture except Okinawa, requesting data on $\mathrm{ABO}$ and $\mathrm{Rh}$ blood groups accumulated at the health centers under the health department. Health departments of 12 prefectures responded to the request. Subsequently, a similar letter was sent to each health center of all other prefectures. Thus, ABO data for more than 500 health centers, in total, were obtained. In several prefectures, such data were available at Red Cross blood centers to which the blood typing was entirely or partly entrusted.

In Kagoshima Prefecture, data on 376,515 high school students in the main island of Kyushu obtained through Prof. Tetuo Zyo and data on 12,336 individuals obtained from 3 health centers in isolated islands were used for the present analyses.

All the materials were blood-typed during the period from April 1964 to March 1975 inclusive, mostly from April 1970 to March 1973.

Most data were classified by the health centers where the blood typing was carried out. In Metropolis Tokyo, data from two or more health centers located in each of ku-districts were combined. Data from Nara Prefecture had been classified by residences of the testees.

Data from all the Red Cross blood centers and those from some prefectural health departments gave only the total of the prefecture. In Fukushima Prefecture, all blood typing were carried out at the Red Cross blood centers, and thus, distribution of blood groups at various districts in the prefecture was unknown.

Thus, ABO data on 4,464,349 individuals were divided into 46 prefectures, and data on $3,292,766$ individuals of the total were divided into 523 subpopulations by health center or district.

In Figs. 6-14 in Appendix, health centers are shown by open circles or $\times$ according to whether the $\mathrm{ABO}$ data were available or not at there, and centers of ku-districts in Tokyo or local centers of regions in Nara and Kagoshima Prefectures are shown by open squares.

Frequencies of phenotypes and alleles of $\mathrm{ABO}$ blood groups, and $\chi^{2}$ values for the deviation from expectation of the random distribution were calculated for (1) data of each health center or district, (2) total of data from all health centers or districts in each prefecture, (3) data from each prefectural department, (4) data from Red Cross blood centers in each prefecture, and (5) grand total of data in each prefecture.

The frequencies of $\mathrm{ABO}$ alleles were estimated using following formulas;

$$
\begin{array}{ll}
\text { Frequency of } I^{\mathrm{A}} & \mathrm{p}=1-\sqrt{\left(\mathrm{n}_{\mathrm{O}}+\mathrm{n}_{\mathrm{B}}\right) / \mathrm{N}}(1+\mathrm{D} / 2), \\
\text { Frequency of } I^{\mathrm{B}} & \mathrm{q}=1-\sqrt{\mathrm{n}_{\mathrm{O}}+\mathrm{n}_{\mathrm{A}} / \mathrm{N}}(1+\mathrm{D} / 2), \\
\text { Frequency of } I^{\mathrm{O}} & \mathrm{r}=\left(\sqrt{\mathrm{n}_{\mathrm{O}} / \mathrm{N}}+\mathrm{D} / 2\right)(1+\mathrm{D} / 2),
\end{array}
$$

where $n_{O}, n_{A}, n_{B}$ and $N$ are, respectively, numbers of $O, A, B$, and all groups in the 
sample, and

$$
\mathrm{D}=1-\sqrt{\left(\mathrm{n}_{\mathrm{O}}+\mathrm{n}_{\mathrm{A}}\right) / \mathrm{N}}-\sqrt{\left(\mathrm{n}_{\mathrm{O}}+\mathrm{n}_{\mathrm{B}}\right) / \mathrm{N}}-\sqrt{\mathrm{n}_{\mathrm{O}} / \mathrm{N}}
$$

$\chi^{2}$ value was calculated from $2 \mathrm{~N}(1+\mathrm{r} / \mathrm{pq}) \mathrm{D}^{2}$ with one degree of freedom.

These values for Data (5), i.e. grand total of each prefecture are summarized in Table 1 and Fig. 2 (an equilateral triangle), and Data (1) to (4) are listed in Appendix.

\section{RESULTS}

Phenotypic frequencies of $\mathrm{ABO}$ blood groups in the whole country are $29.25 \%$

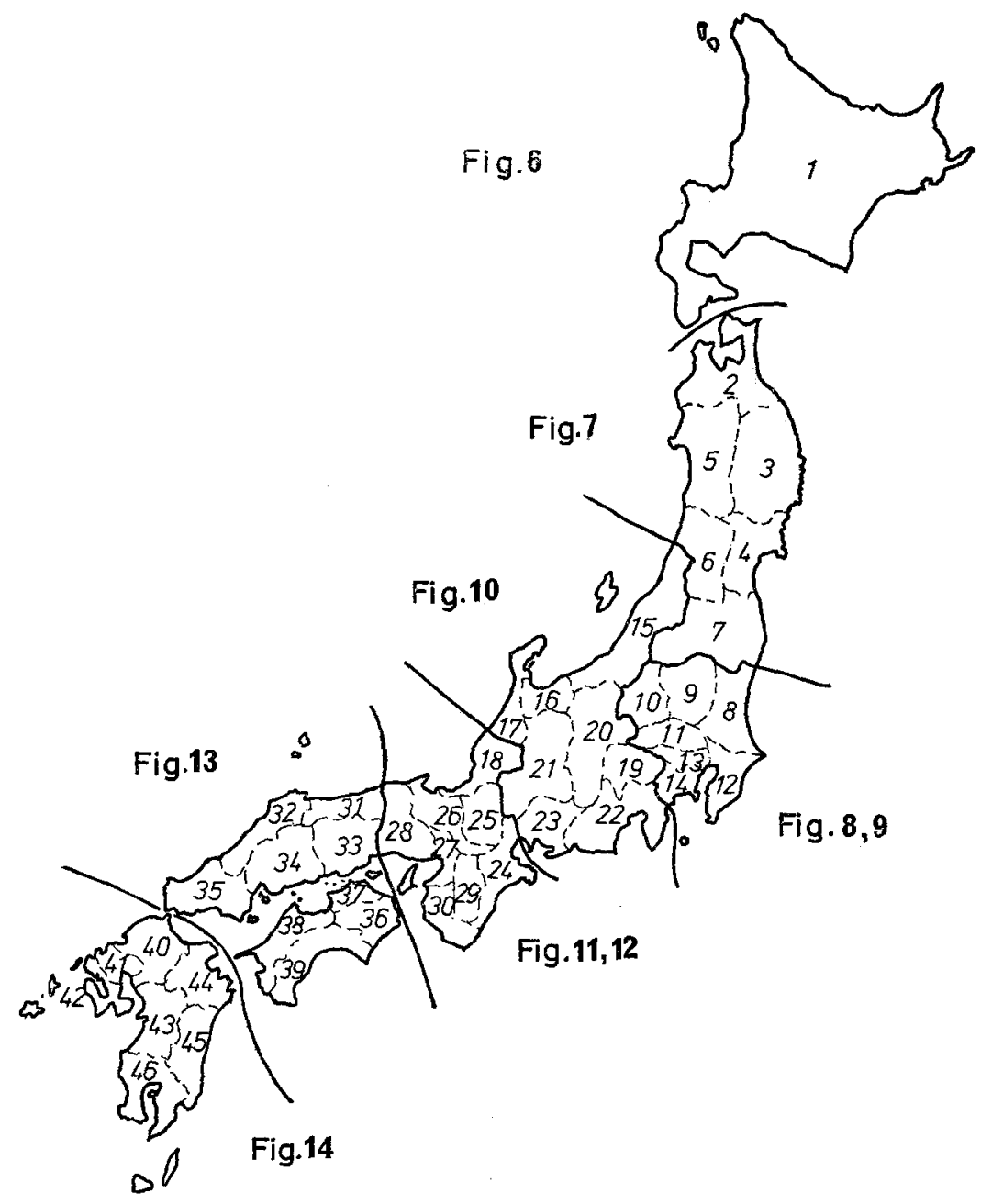

Fig. 1. Prefectures in Japan. The numbers correspond to those in Table 1. 


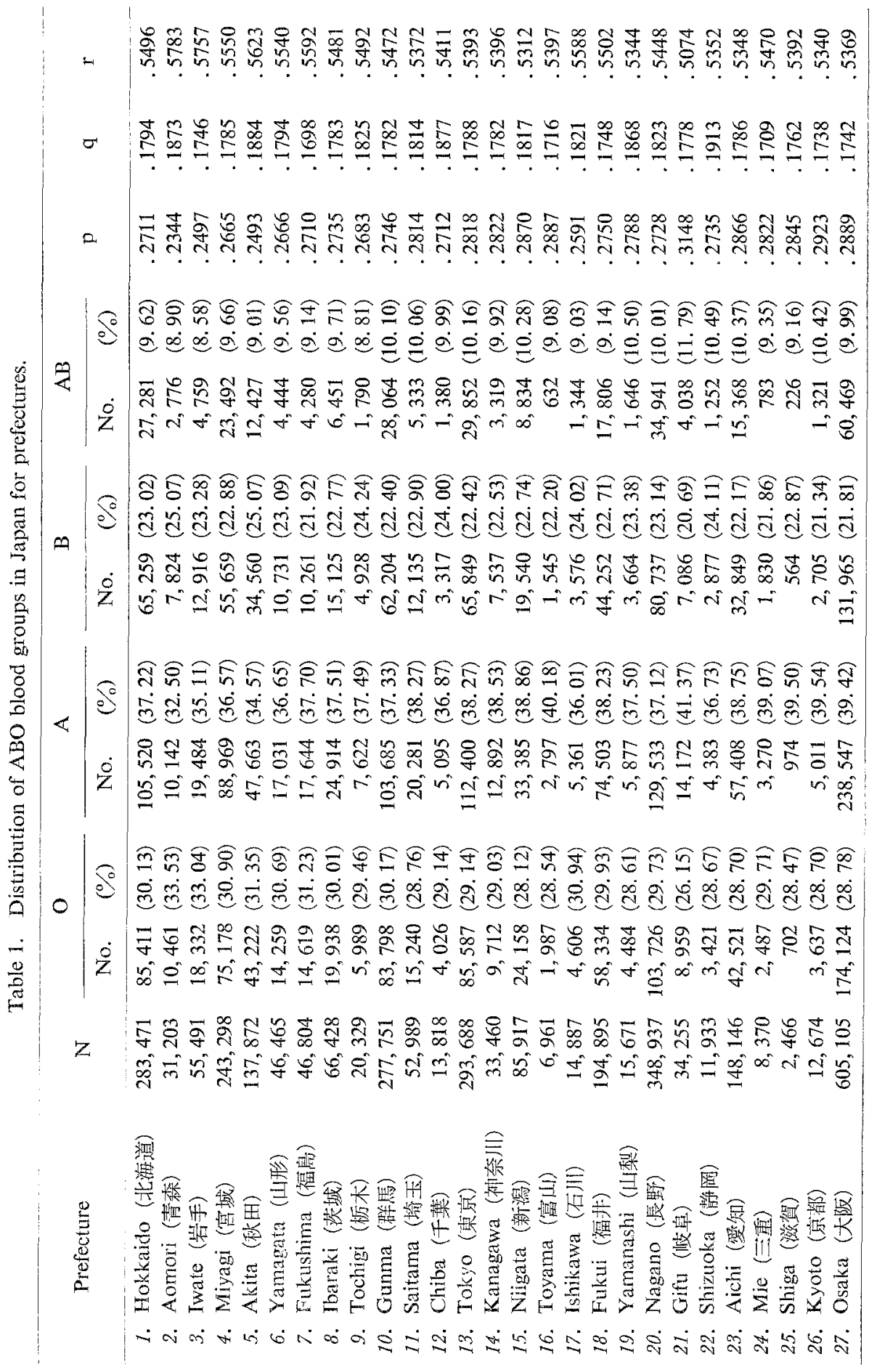




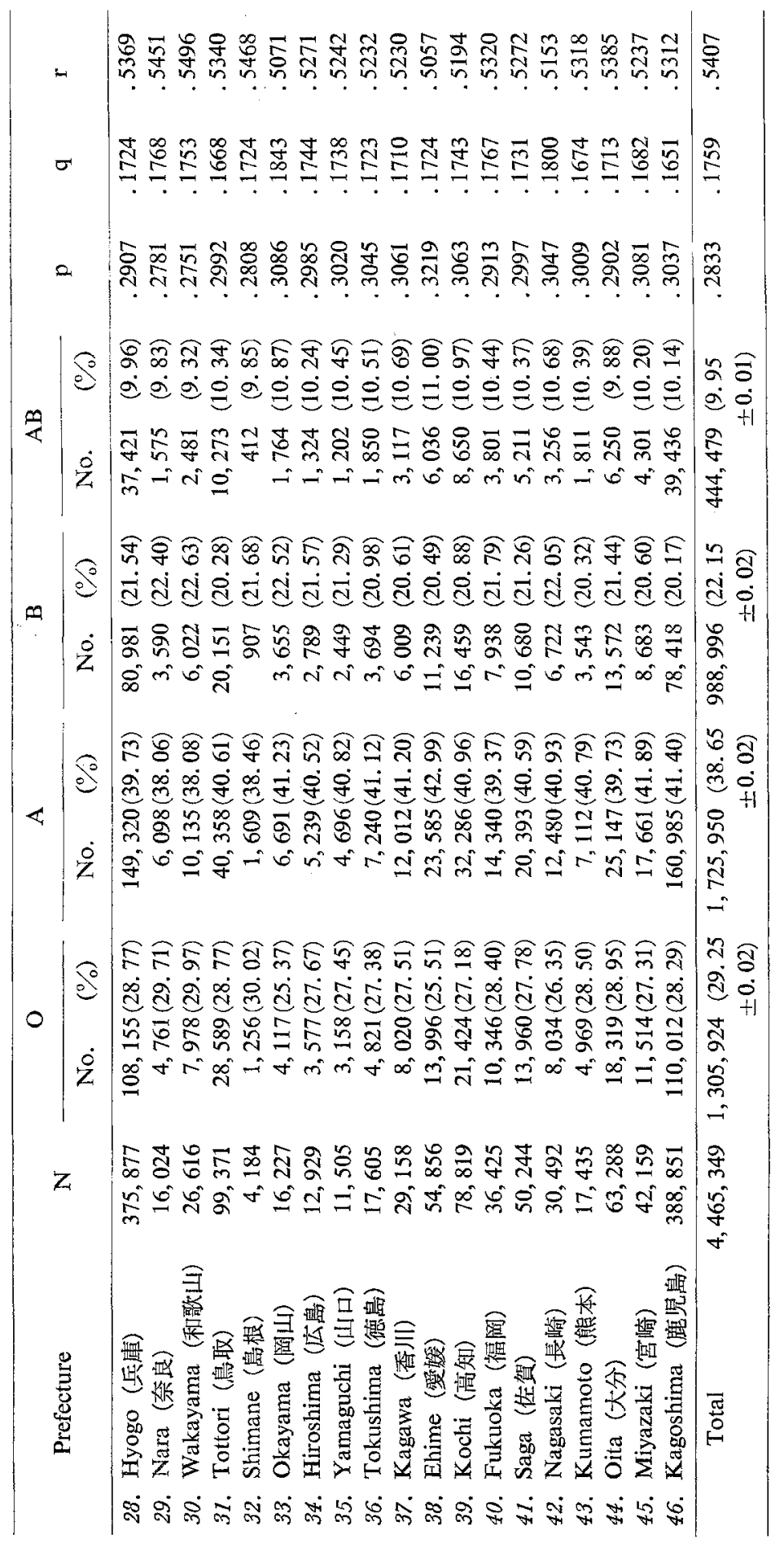




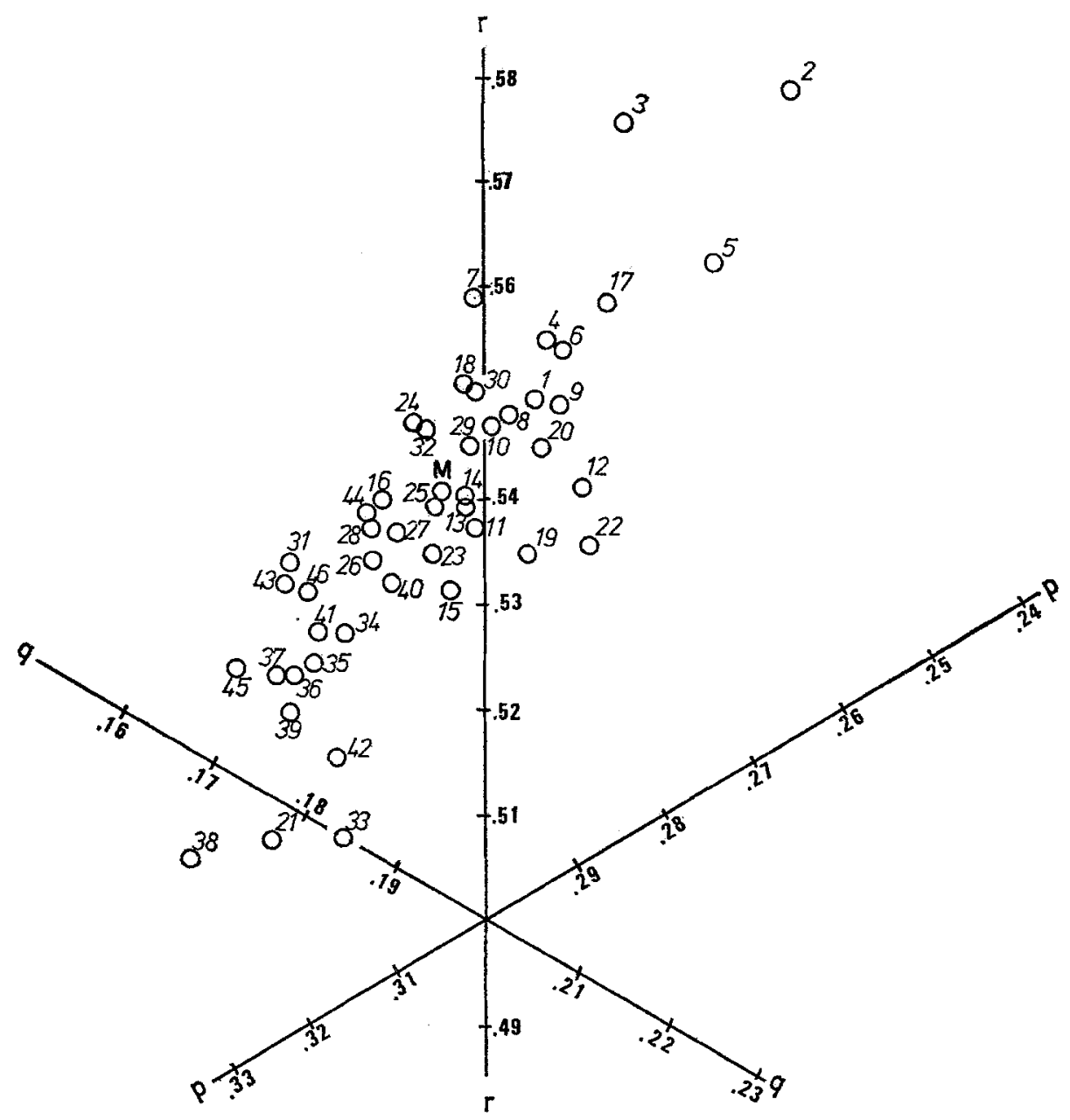

Fig. 2. Distribution of $A B O$ gene frequencies in Japan. M: Mean of the whole country.

$\mathrm{O}, 38.65 \% \mathrm{~A}, 22.15 \% \mathrm{~B}$, and $9.95 \% \mathrm{AB}$. Gene frequencies are estimated to be $\mathrm{p}\left(I^{\mathrm{A}}\right)=0.2833, \mathrm{q}\left(I^{\mathrm{B}}\right)=0.1759$, and $\mathrm{r}\left(I^{\circ}\right)=0.5407$.

Table 1 and the equilateral triangle (Fig. 2) indicate gradients of the gene frequencies, the $I^{\Delta}$ allele being increased and $I^{B}$ and $I^{0}$ alleles being decreased from the northeast to the southwest. The distance of each prefecture capital from an arbitrary origin, Aomori, the northernmost of Honshu Island, was measured in 1,000 kilometers along the National Railroads. Hokkaido was excluded from this analysis, since nearly all of the present population of the island consist of relatively recent immigrants from all localities of Japan and their progenies. The relationships between the distances and frequencies of $I^{\mathrm{A}}, I^{\mathrm{B}}$, and $I^{\mathrm{O}}$ are shown in Figs. 3-5.

The correlation coefficients between the distance and the gene frequencies, 


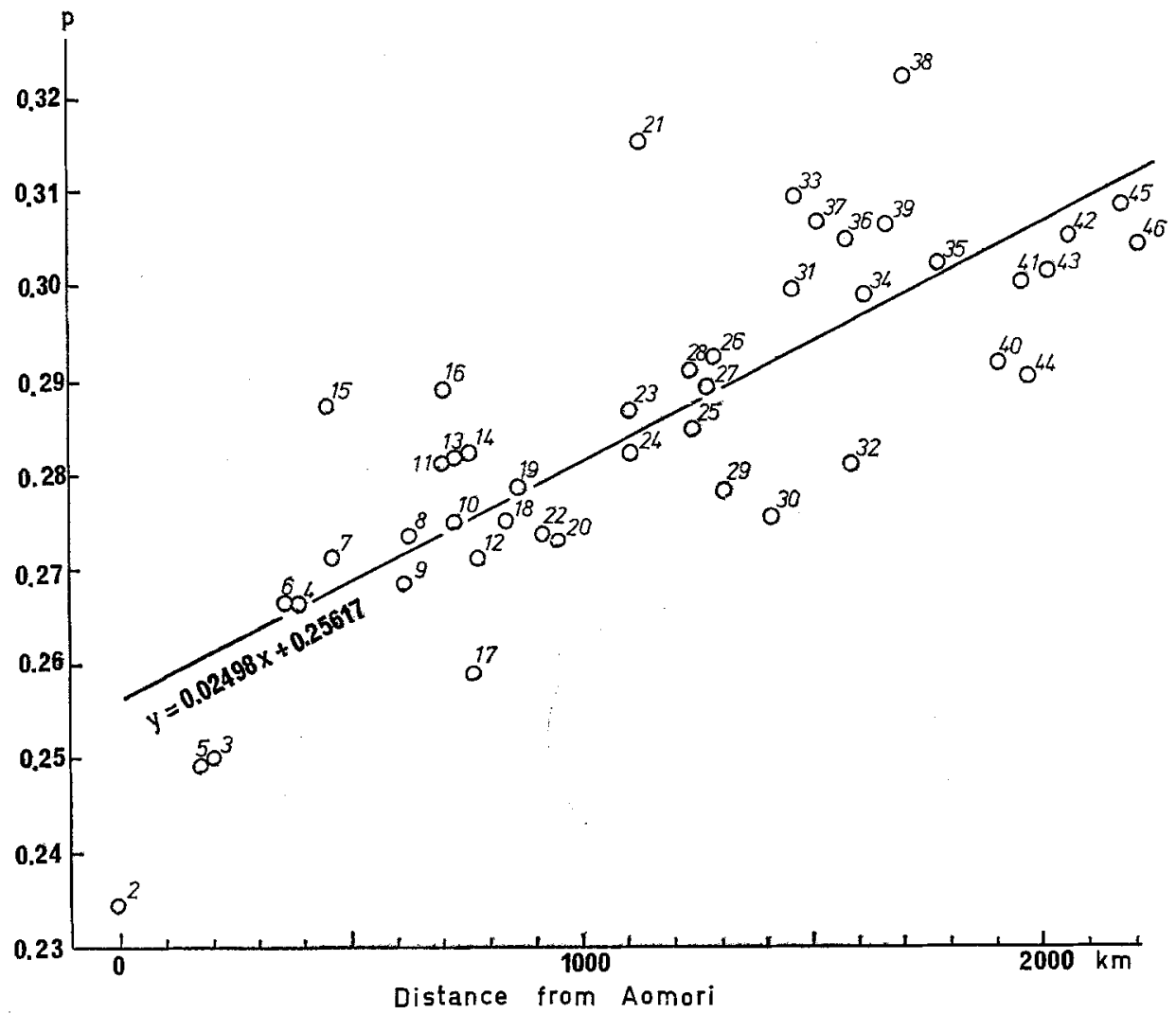

Fig. 3. Gradient of the frequency of $I^{\mathrm{A}}$ allele, $p$.

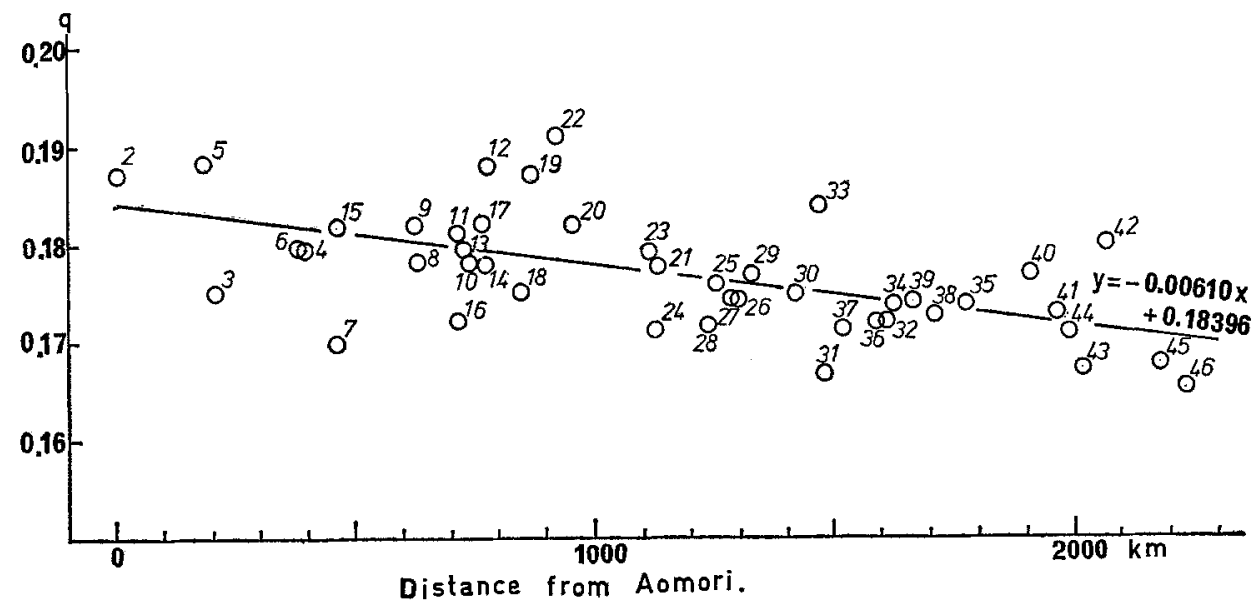

Fig. 4. Gradient of the frequency of $I^{\mathrm{B}}$ allele, $\mathrm{q}$. 


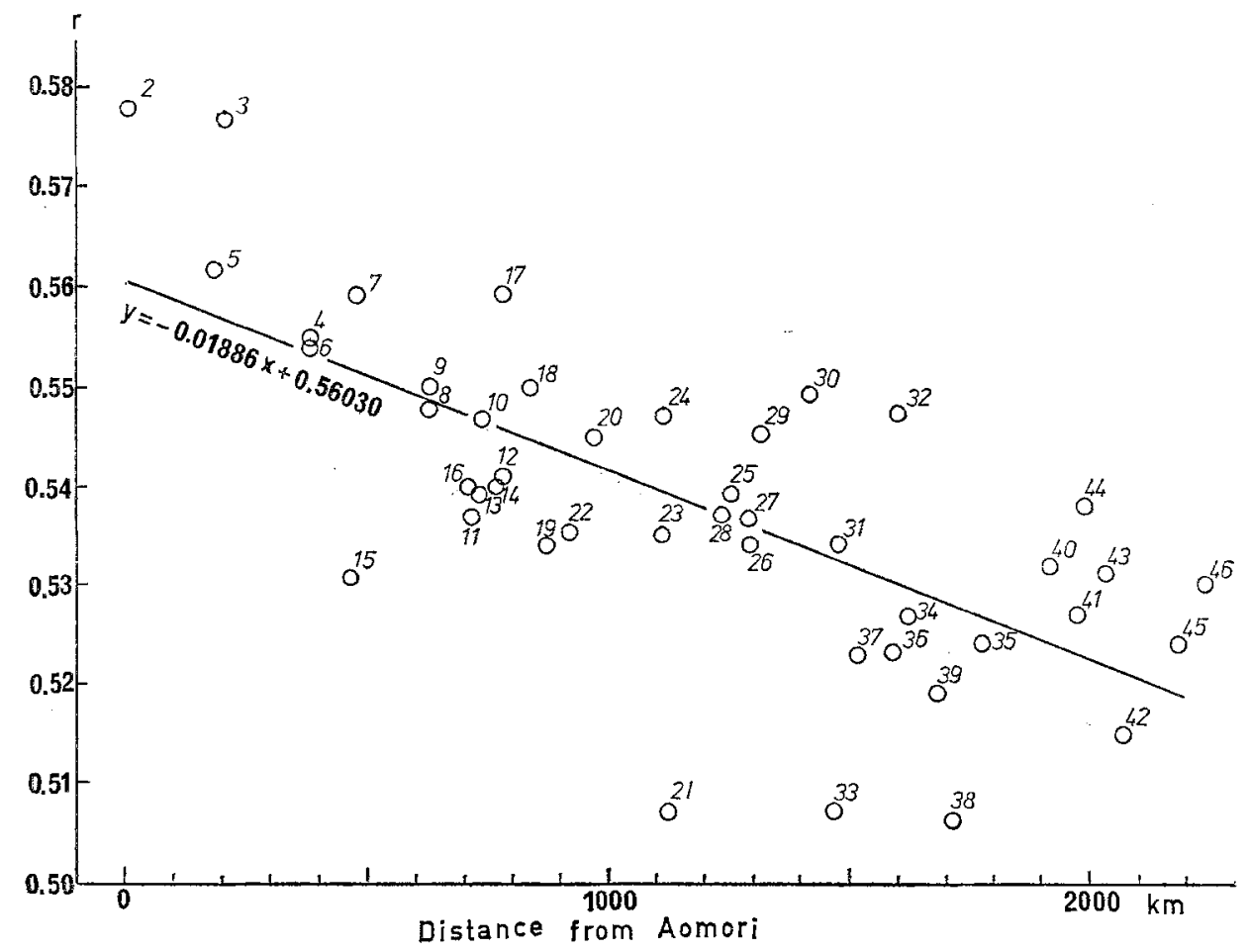

Fig. 5. Gradient of the frequency of $I^{\circ}$ allele, $r$.

and the regression coefficients of the gene frequencies on the distance are summarized as follows:

Correlation coefficient

$\mathrm{p}$

$\mathrm{q}$

$\mathrm{r}$
0.80384

$-0.58602$

$-0.69657$
Regression coefficient

0.02498

$-0.00610$

$-0.01886$

The correlation coefficients are all highly significant at the $0.1 \%$ level, with the $t$ values 8.922 for $I^{\mathrm{A}},-4.700$ for $I^{\mathrm{B}}$, and -6.535 for $I^{\mathrm{O}}$ with 43 degrees of freedom.

\section{DISCUSSION}

The present analysis of the data on more than four million Japanese collected from the whole country showed the frequencies of $\mathrm{ABO}$ blood groups to be $\mathrm{O}$ : $29.25 \pm 0.02 \%, \mathrm{~A}: 38.65 \pm 0.02 \%, \mathrm{~B}: 22.15 \pm 0.02 \%$, and $\mathrm{AB}: 9.95 \pm 0.01 \%$. These figures cannot be regarded as an exact representatives of the Japanese population, since the samples were, by no means, randomly chosen from various subpopulations which are different in the $\mathrm{ABO}$ frequencies from each other.

According to Furuhata (1933), frequencies of ABO blood groups for con- 
scripts, 121,200 in number, tested at the physical examination were $29.86 \% \mathrm{O}$, $38.23 \% \mathrm{~A}, 22.26 \% \mathrm{~B}$, and $9.65 \% \mathrm{AB}$. The sample may be regarded as a nearly ideal representative of Japanese population and the figures were rather similar to those obtained in the present study. On the other hand, there are some indications that the frequencies of $\mathrm{ABO}$ blood groups have changed in the recent years. According to Kobayasi (1940), phenotypic frequencies of $\mathrm{ABO}$ blood groups in 530,046 Japanese were O: $30.46 \pm 0.06 \%, A: 38.35 \pm 0.07 \%, B: 21.77 \pm 0.06 \%$, and $\mathrm{AB}$ : $9.42 \pm 0.04 \%$. If inhabitants in Okinawa and outside the present territory of Japan were excluded from her materials, the $\mathrm{ABO}$ frequencies in remaining 461,313 resided in the 46 prefectures corresponding to the area studied in the present communication are O: $30.43 \%, \mathrm{~A}: 38.37 \%, \mathrm{~B}: 21.79 \%$, and $\mathrm{AB}: 9.41 \%$, quite similar to the frequencies obtained from her whole materials.

These figures, however, differ significantly from those obtained by the present study. There are a relative decrease in group $O$ and relative increases in groups $\mathrm{A}, \mathrm{B}$, and $\mathrm{AB}$ in 30 years. The change is the largest in the $\mathrm{O}$ frequency. Similar tendencies are observed in a majority of prefectures. Such differences may be resulted from various causes as follows:

1) At least a part of these discrepancies may be only sampling errors.

2) There are some evidences that technical errors in blood typing were much more frequent before 10 years or earlier than in the recent days.

3) Since, data compiled by Kobayasi and by the present authors were not random samples from each subpopulation of the country, the differences in $\mathrm{ABO}$ distributions between the two data may be attributable partly to differences among localities where the samples were taken and the relative size of the samples.

4) Recent drastic migration had an important role in the changes of the $\mathrm{ABO}$ distribution. According to a report from the Statistic Bureau, Prime Ministry Office (1974), $2.5-4.1 \%$ of Japanese population had migrated yearly beyond boundary of prefectures and other $3.2-4.0 \%$ within prefecture during the period from 1950 to 1970 . Immigration into great cities was most remarkable. The population of Metropolis Tokyo, for instance, has increased from 5.0 millions in 1947 to 11.7 millions in 1975, and more than a half of the increase was estimated to be immigrants from all over the country.

However, the migration has not changed the gradient of $\mathrm{ABO}$ distribution; that is, the regression coefficients of $I^{\mathrm{A}}, I^{\mathrm{B}}$, and $I^{\mathrm{O}}$ gene frequencies on the distances from Aomori are estimated to be $0.02498,-0.00610$, and -0.01886 respectively, which reveal no signs of decrease from the estimates by Nei and Imaizumi (1966), $0.0243,-0.0093$, and -0.0150 respectively based upon data cited from literature published from 1922 to 1963 , mostly prior to 1940 .

5) A systematic decrease in group $O$ may be resulted, at least, from increasing breakdown of isolates in Japan. If a population was composed of many subpopulations differing in the gene frequency from each other, frequency of homozygotes in the entire population may be expressed by 


$$
\frac{1}{N} \sum_{i=1}^{n} f_{i} x^{2}=\bar{x}^{2}+V_{x}
$$

where $x_{I}$ and $f_{I}$ are the gene frequency and number of individuals in i-th subpopulation, $V_{x}$ is the variance of $x$, and $N$ is the total number of individuals in the entire population.

With the advance of the isolate breakdown, differences in the gene frequency among subpopulations tend to decrease resulting in $V_{x \rightarrow 0}$. Thus, the frequency of group $\mathrm{O}$, all homozygotes, may decrease, and those of $\mathrm{A}, \mathrm{B}$, and $\mathrm{AB}$ groups increased, since about $80 \%, 87 \%$ and $100 \%$ of these groups, respectively, are heterozygotes in Japanese population. The effects of isolate breakdown on the distribution of $\mathrm{ABO}$ blood groups will be discussed in more detail elsewhere.

Acknowledgment The authors are indebted to Drs. Hachiro Nakajima and Yoko Imaizumi for valuable advices.

Particular thanks are due to Prof. T. Zyo, Prefectural Health Departments, Health Centers, and Red Cross Blood Centers for the cooperation in the collection of the data.

\section{REFERENCES}

Akaishi, S. and Kudo, T. 1975. Blood groups. In JIBP Synthesis: Human Adaptability, Vol. 2, Anthropological and Genetic Studies on the Japanese (S. Watanabe, S. Kondo, and E. Matsunaga, eds.), pp. 77-107. Univ. of Tokyo Press, Tokyo.

Bureau of Statistics, Office of the Prime Ministry, Japan. 1974. Annual Report on the Internal Migration in Japan Derived from the Basic Resident Registers.

Furuhata, T. 1925. Japanese and Ainu from the viewpoint of serology (in Japanese). Nihon Gakujutsu Kyokai Hokoku (Proc. Jap. Acad. Soc.) 1: 325-339.

Furuhata, T. 1933. On the serological position of the Japanese (in Japanese). Nihon Gakujutsu Kyokai Hokoku (Proc. Jap. Acad. Soc.) 8: 564-573.

Kobayasi, T. 1940. Statistische Beobachtung der Bluttypenverteilung im ABO-System bei Japanern (in Japanese). Hanzaigaku Zassi (Archiv für Gerichtliche Medizin und Kriminologie) 14: 727-735.

Nei, M. and Imaizumi, Y. 1966. Genetic structure of human populations. I. Local differentiation of blood group gene frequencies in Japan. Heredity 21 : 9-35.

Tanaka, T. 1959. A study on the Japanese from the standpoint of the blood groups (in Japanese with English summary). Hanzaigaku Zasshi (Jap. J. of Legal Med. and Criminol.) 25: 37-67. 


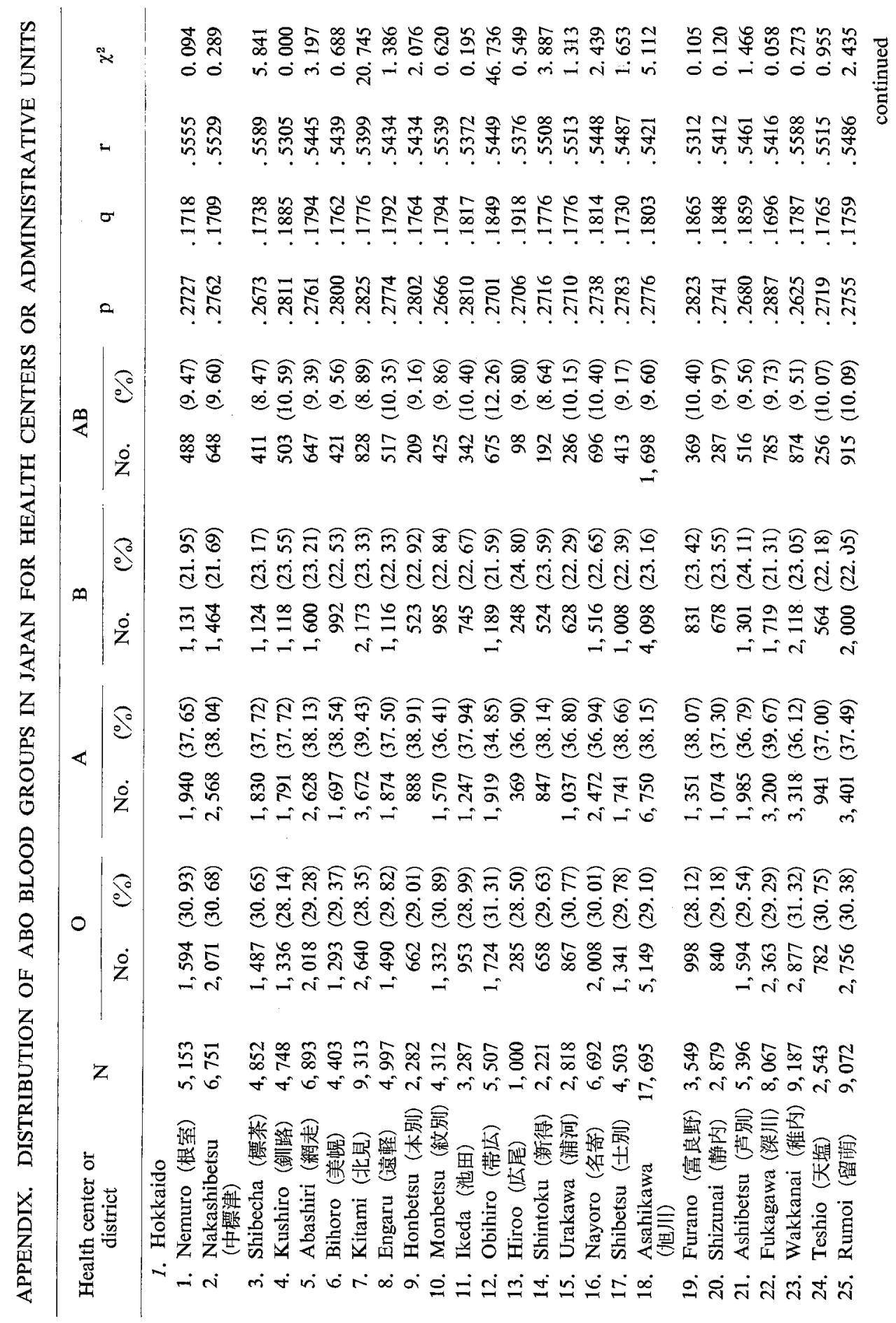




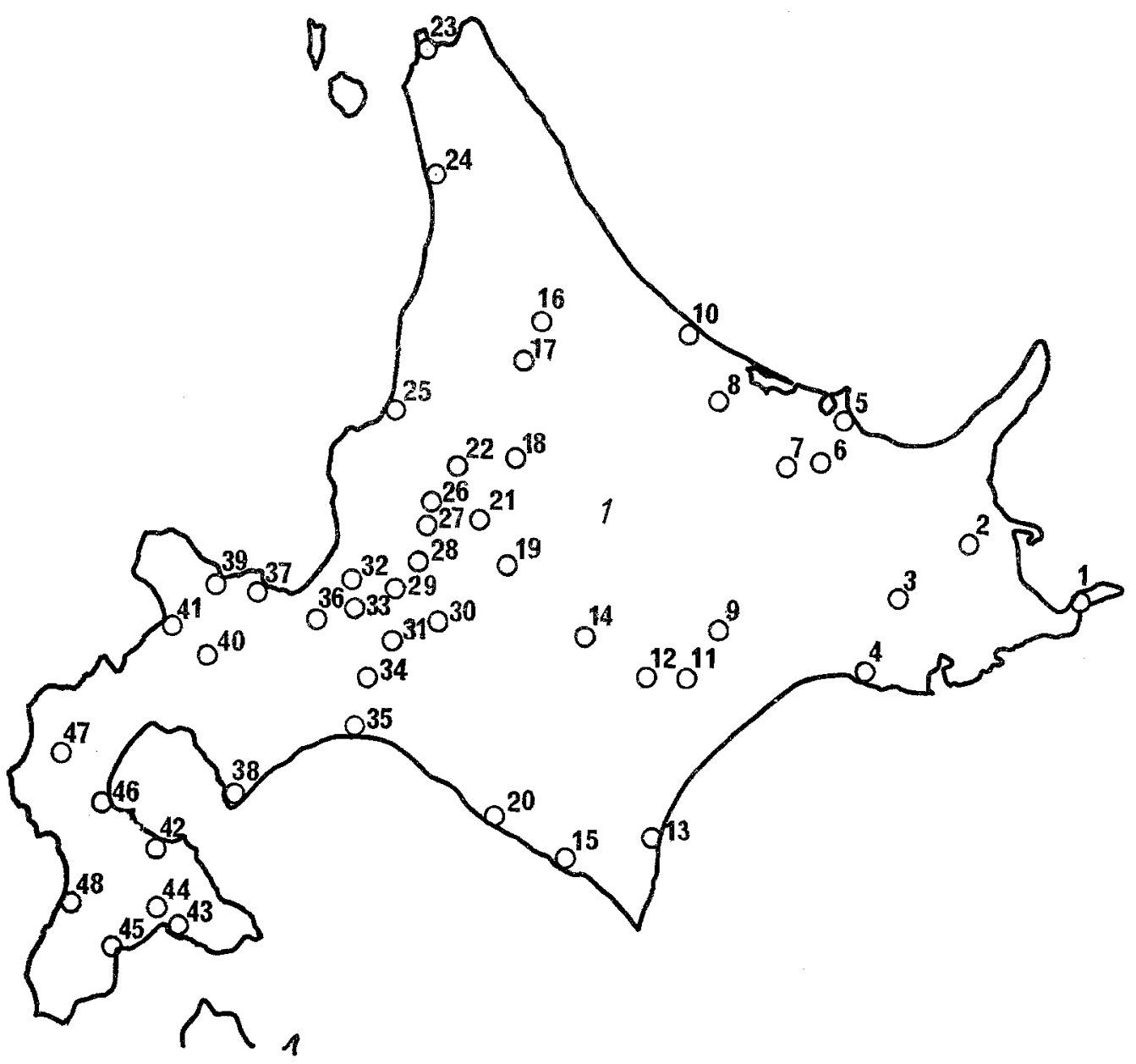

Fig. 6. Hokkaido (Prefecture 1). 


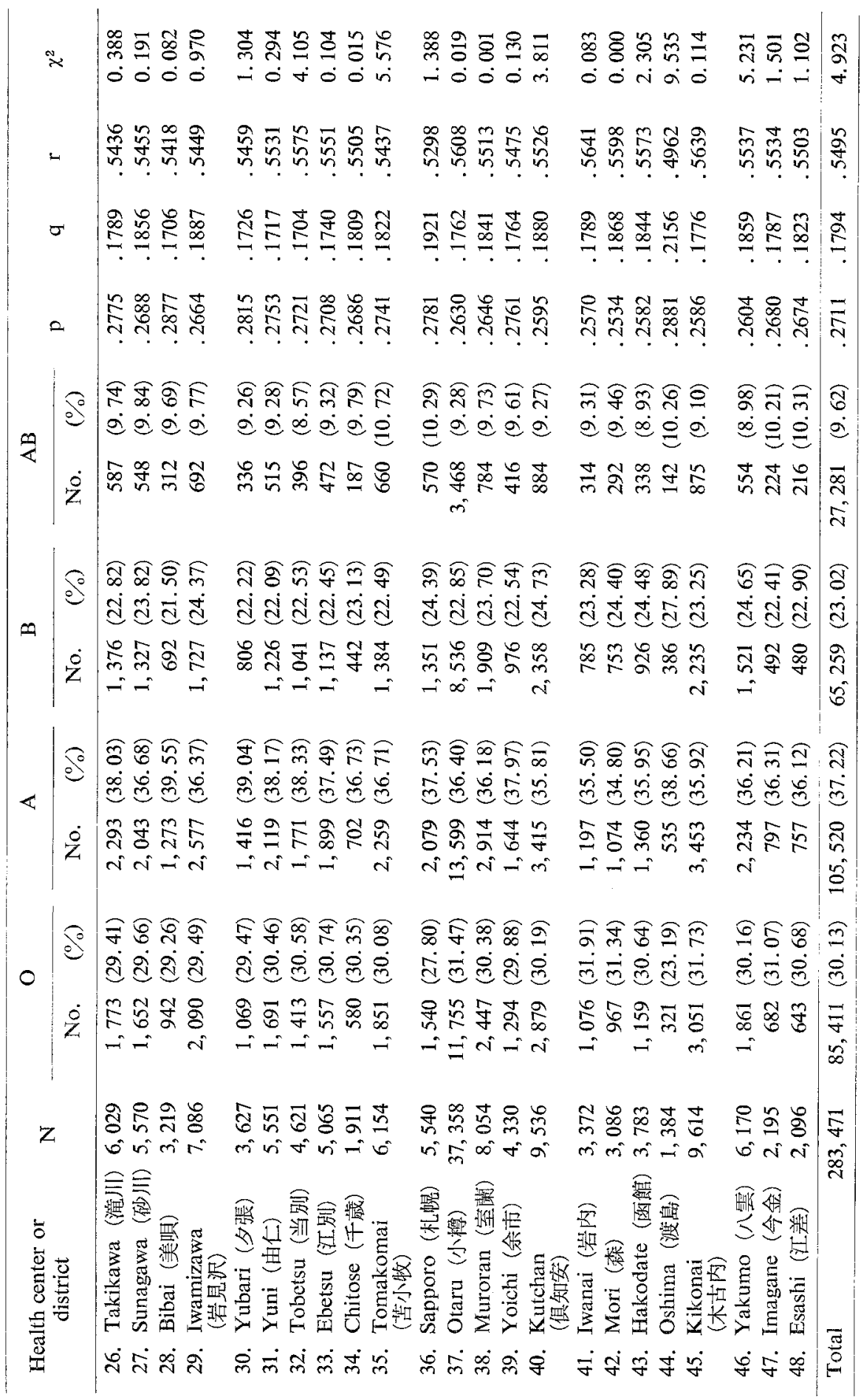




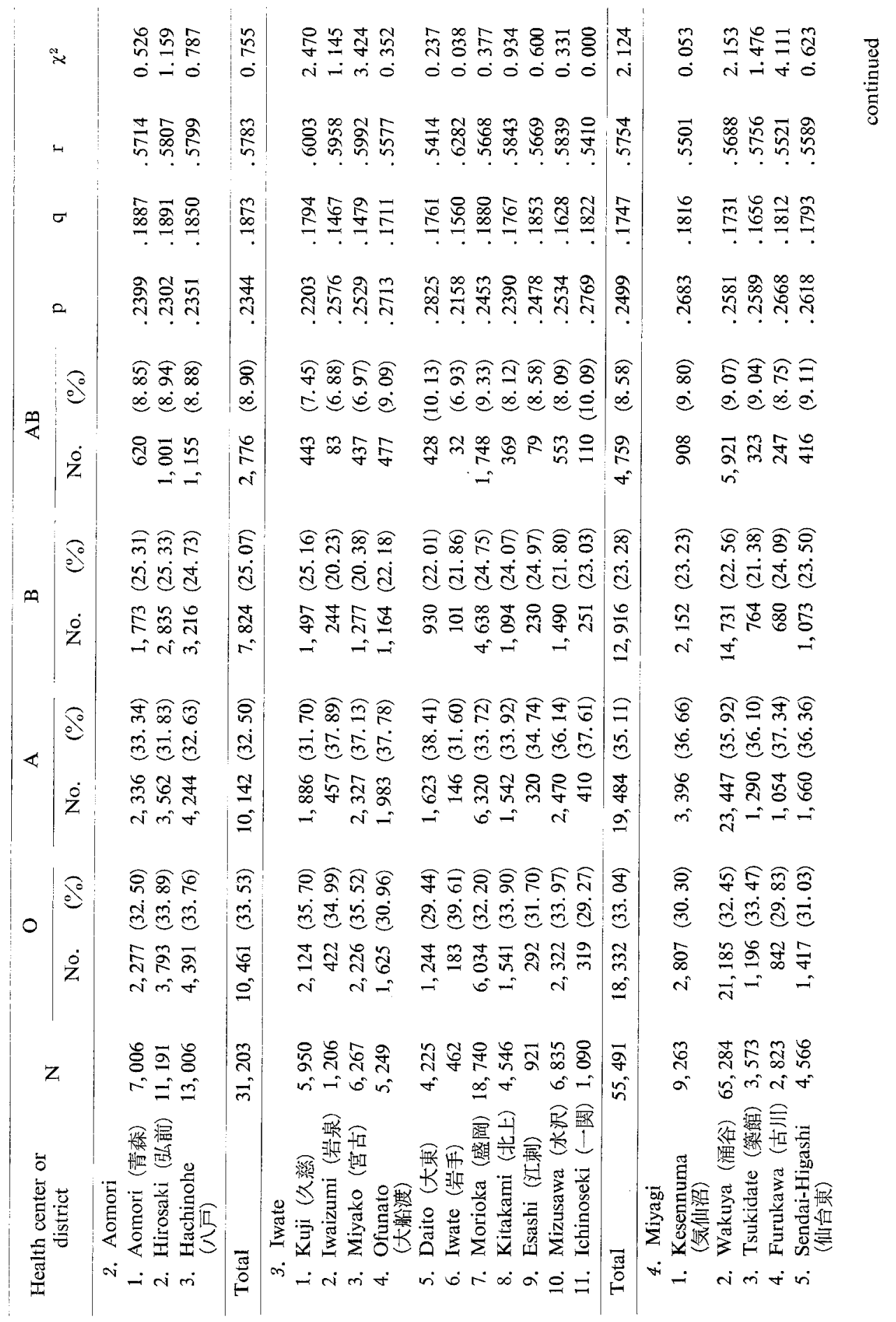




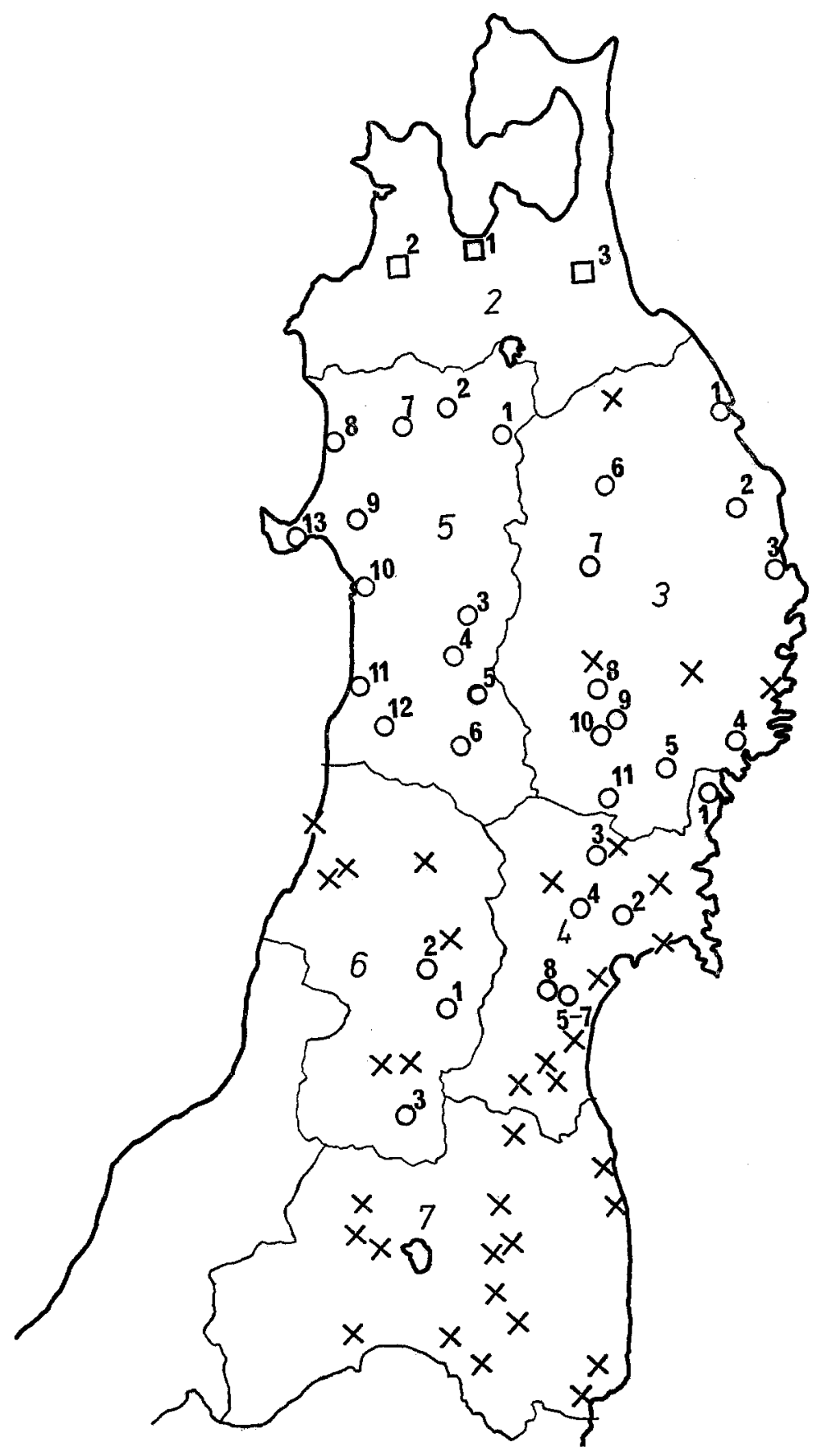

Fig. 7. Tohoku District (Prefectures 2-7). 


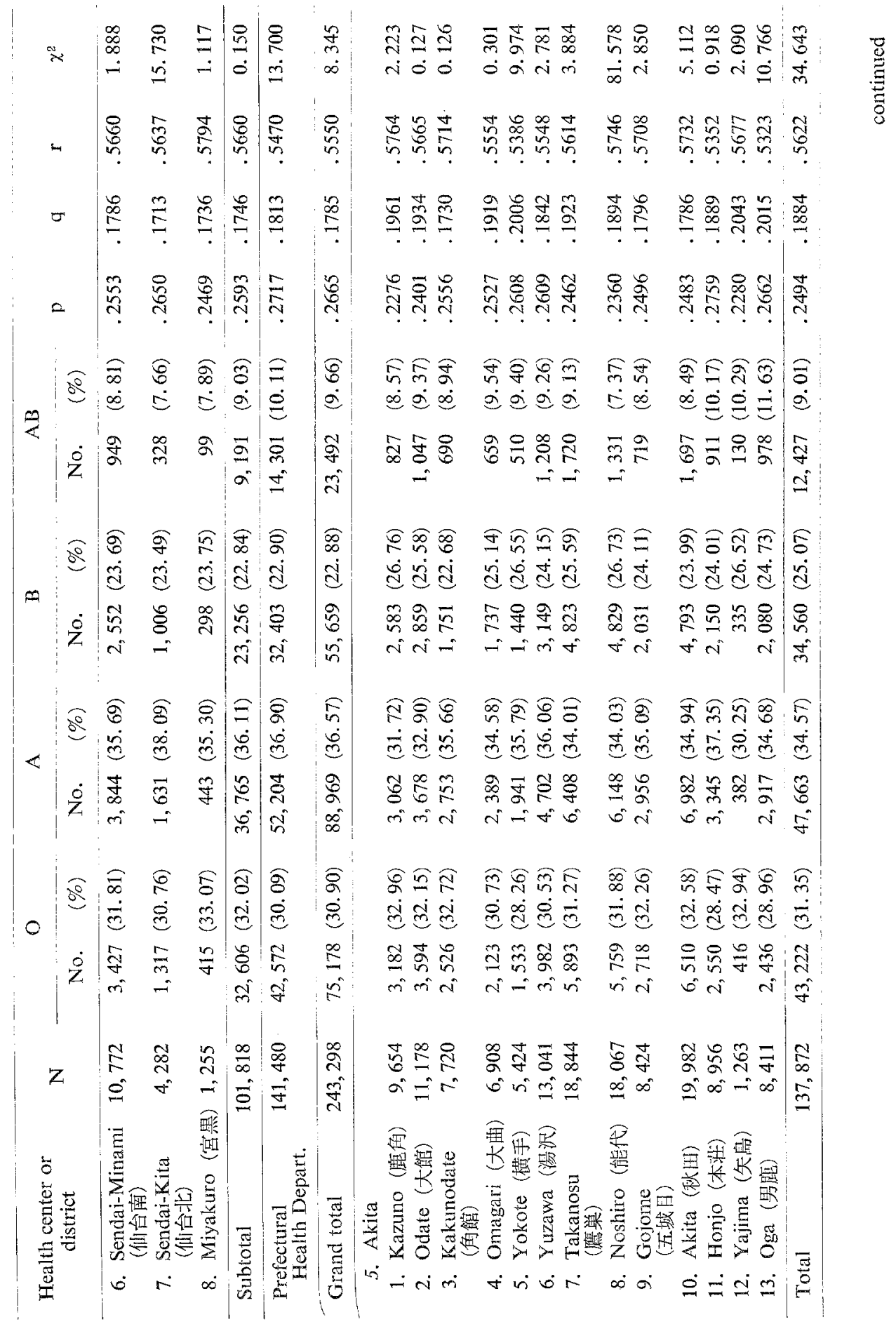




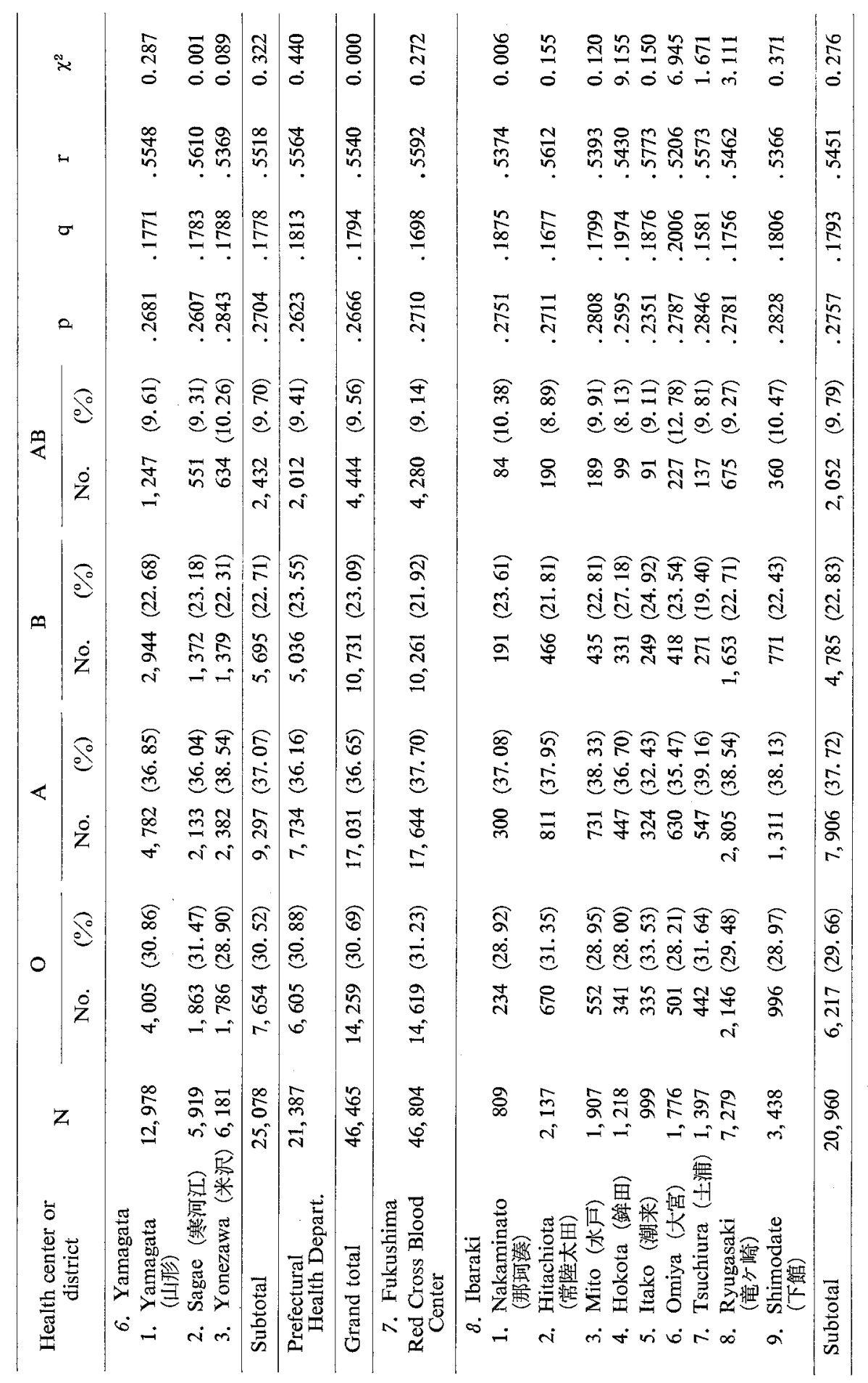




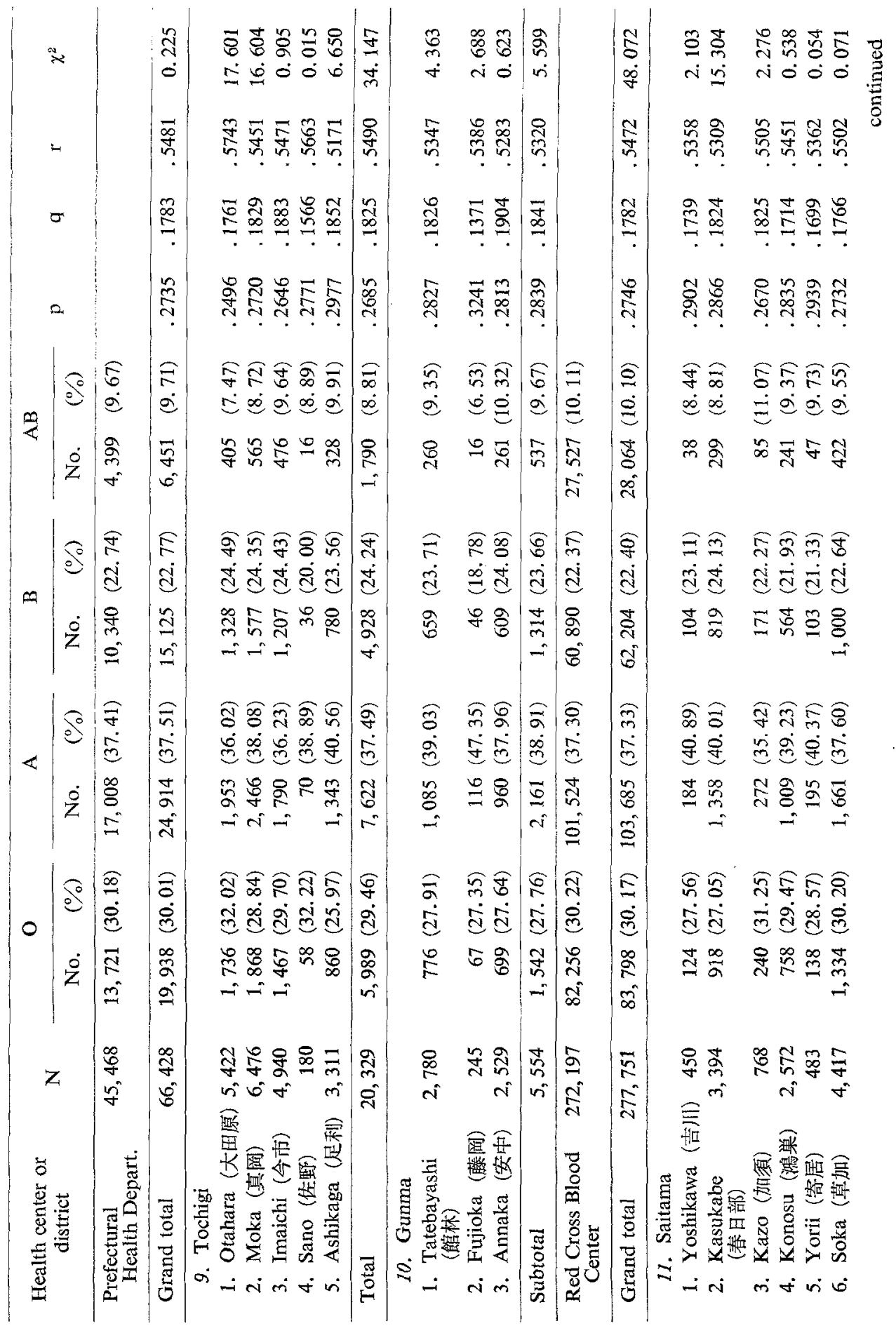




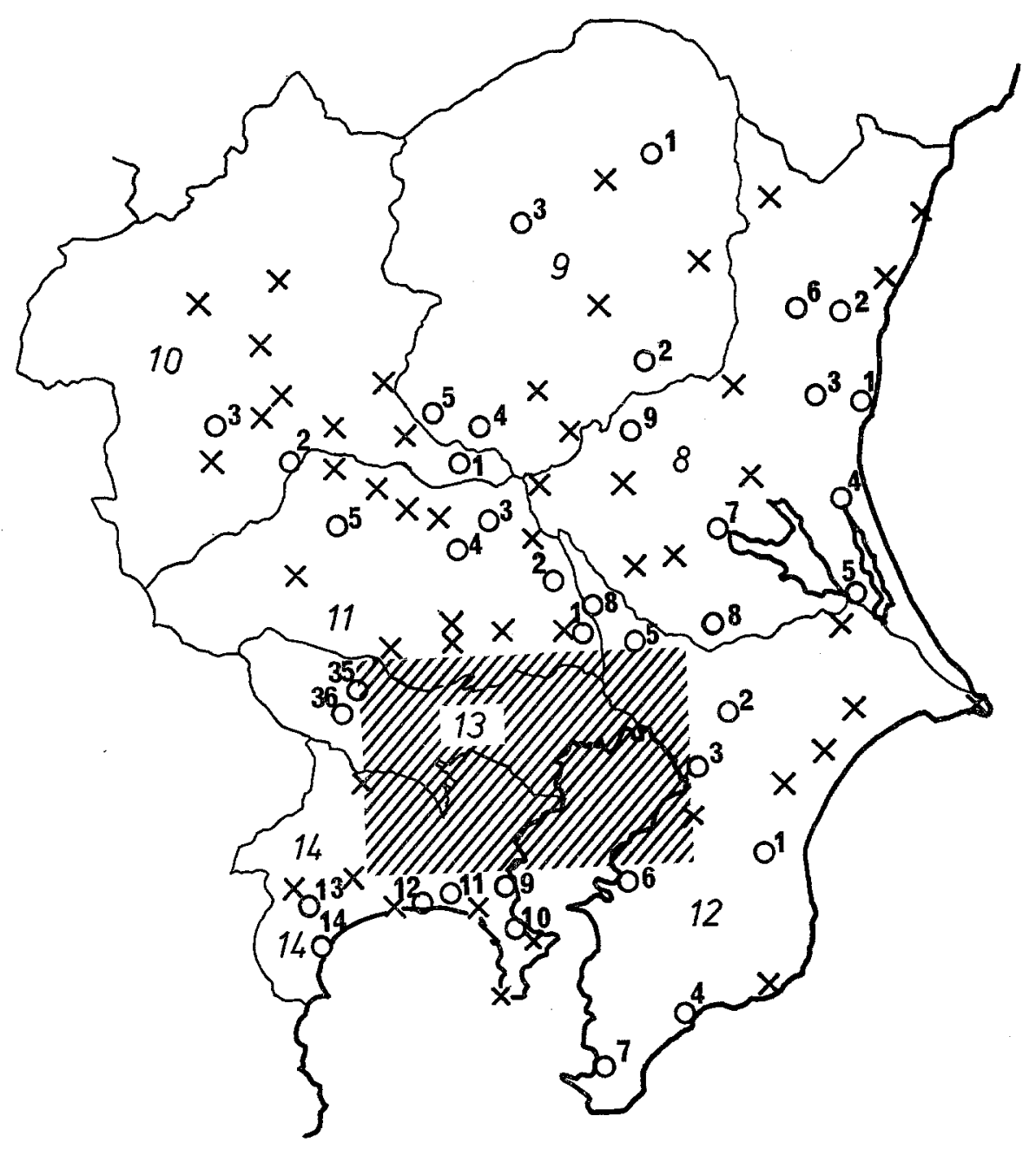

Fig. 8. Kanto District (Prefectures 8-14). 
82

Y. FUJITA, M. TANIMURA, and K. TANAKA

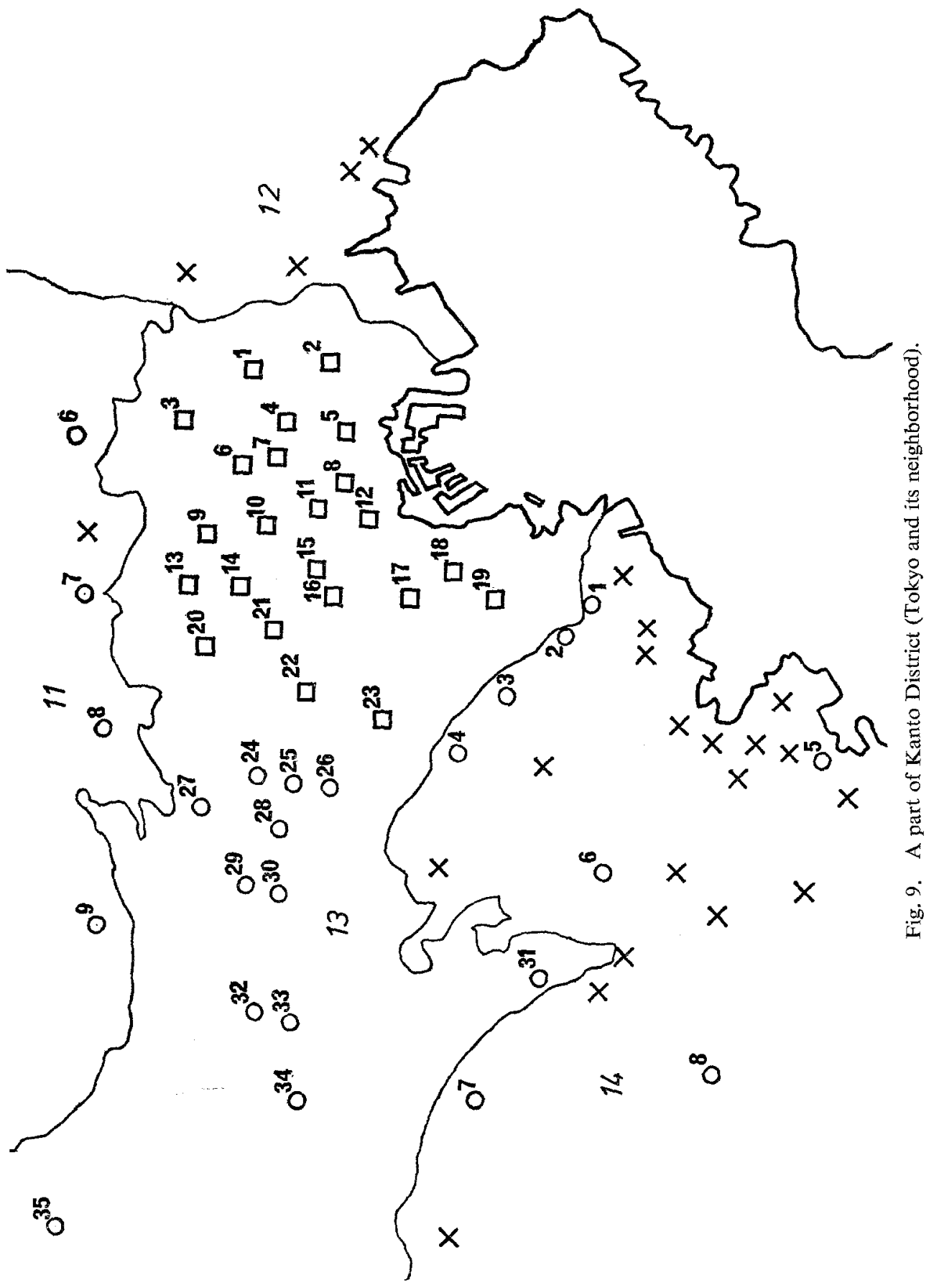




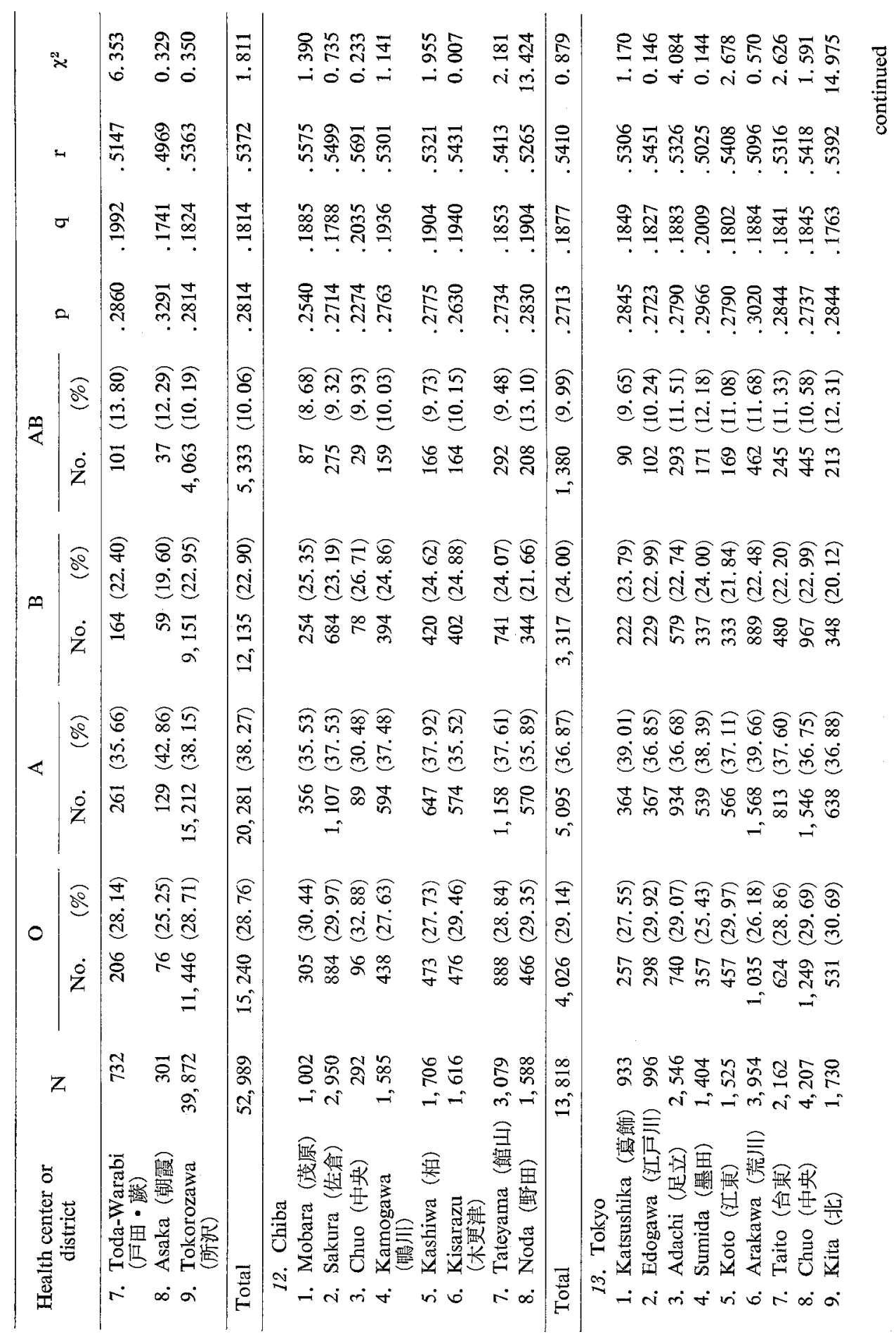




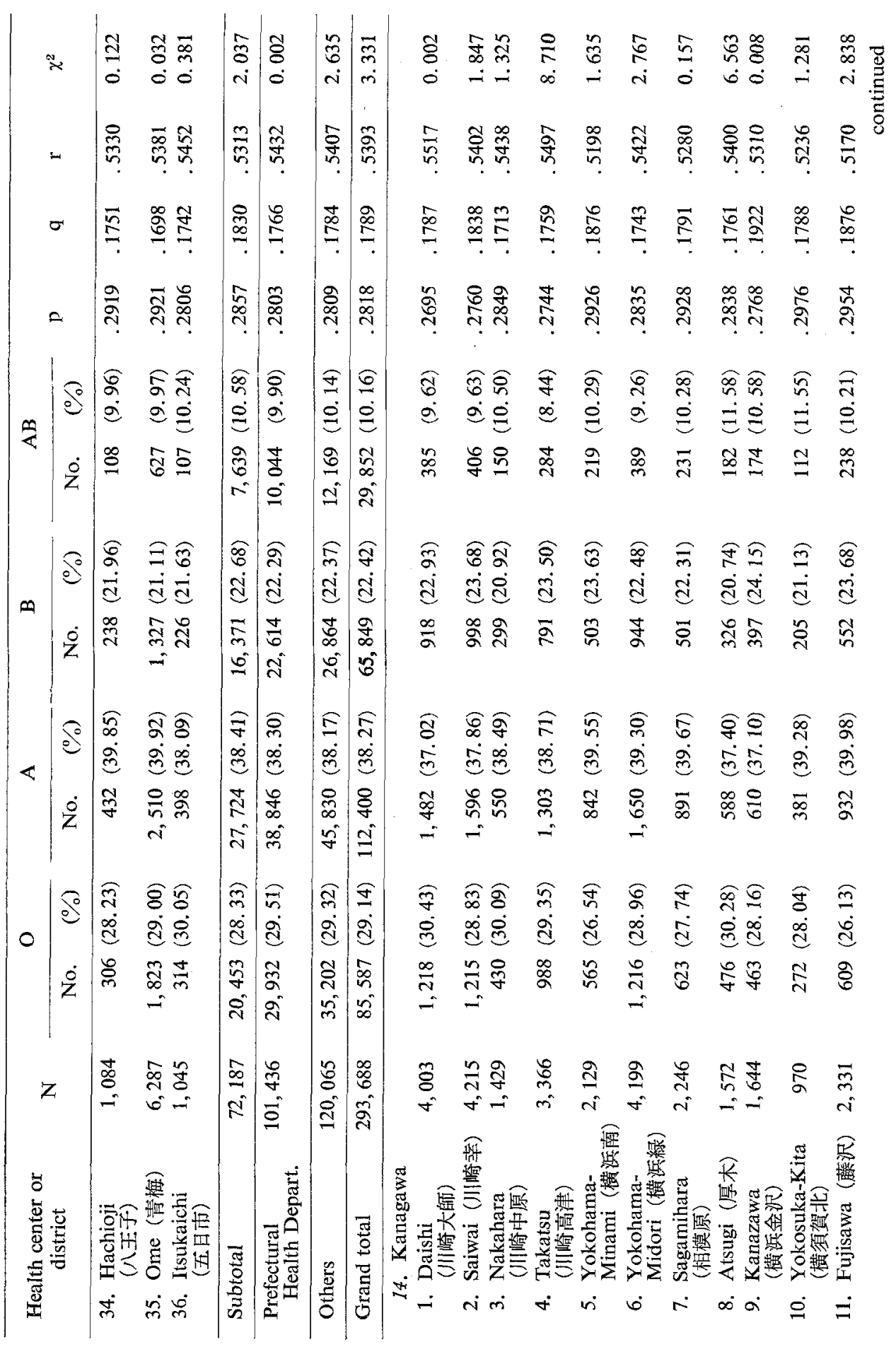




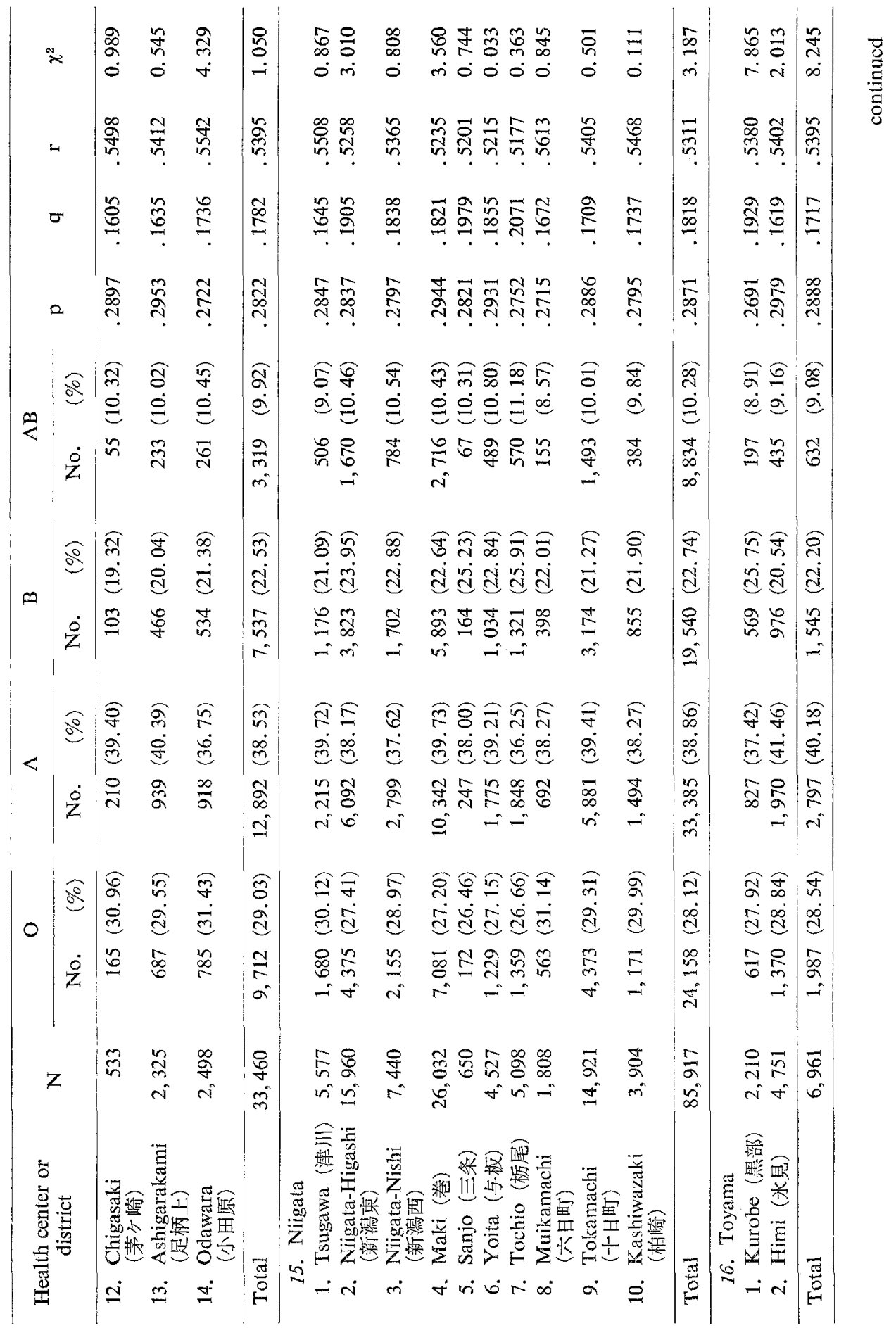




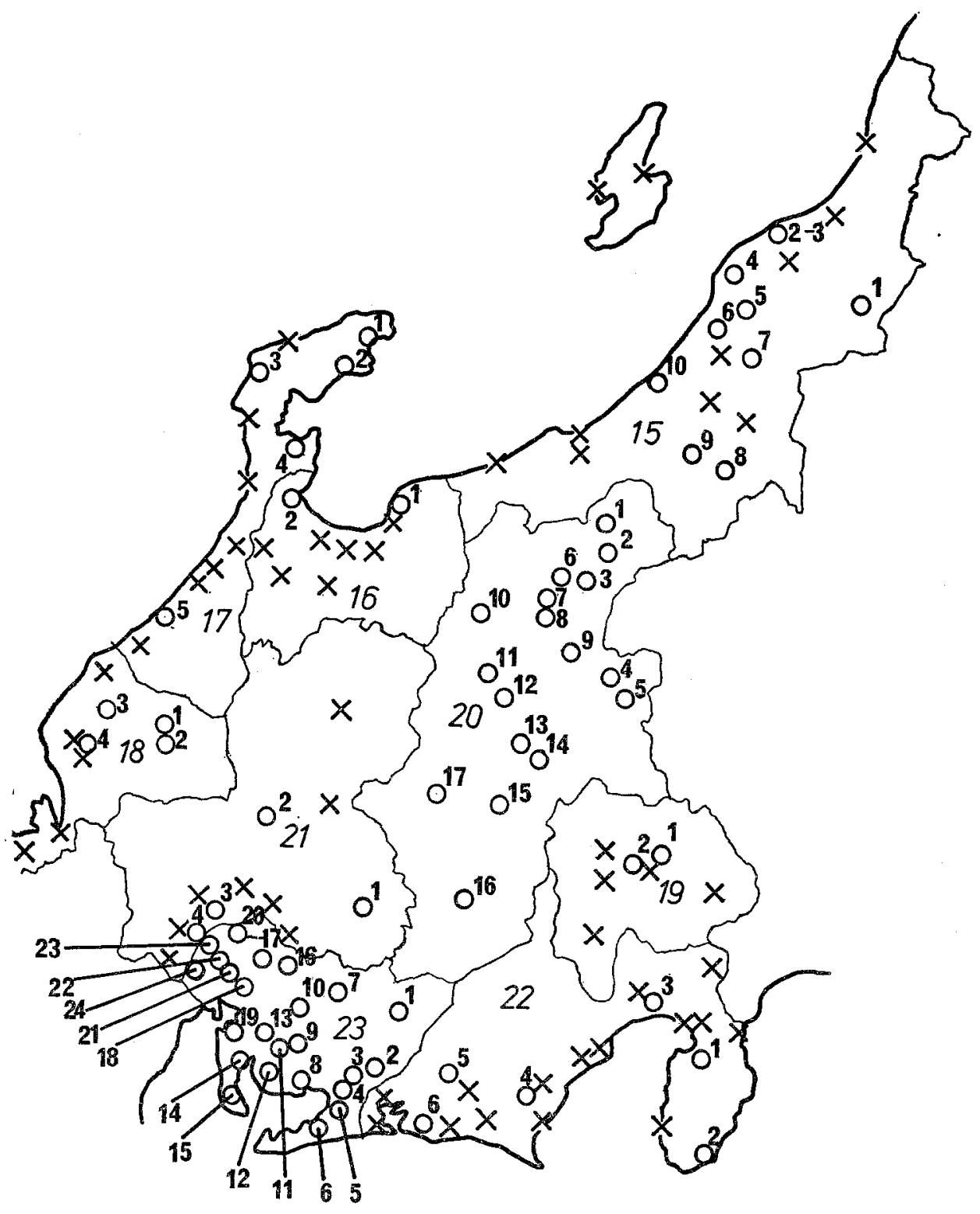

Fig. 10. Chubu District (Prefectures 15-23). 


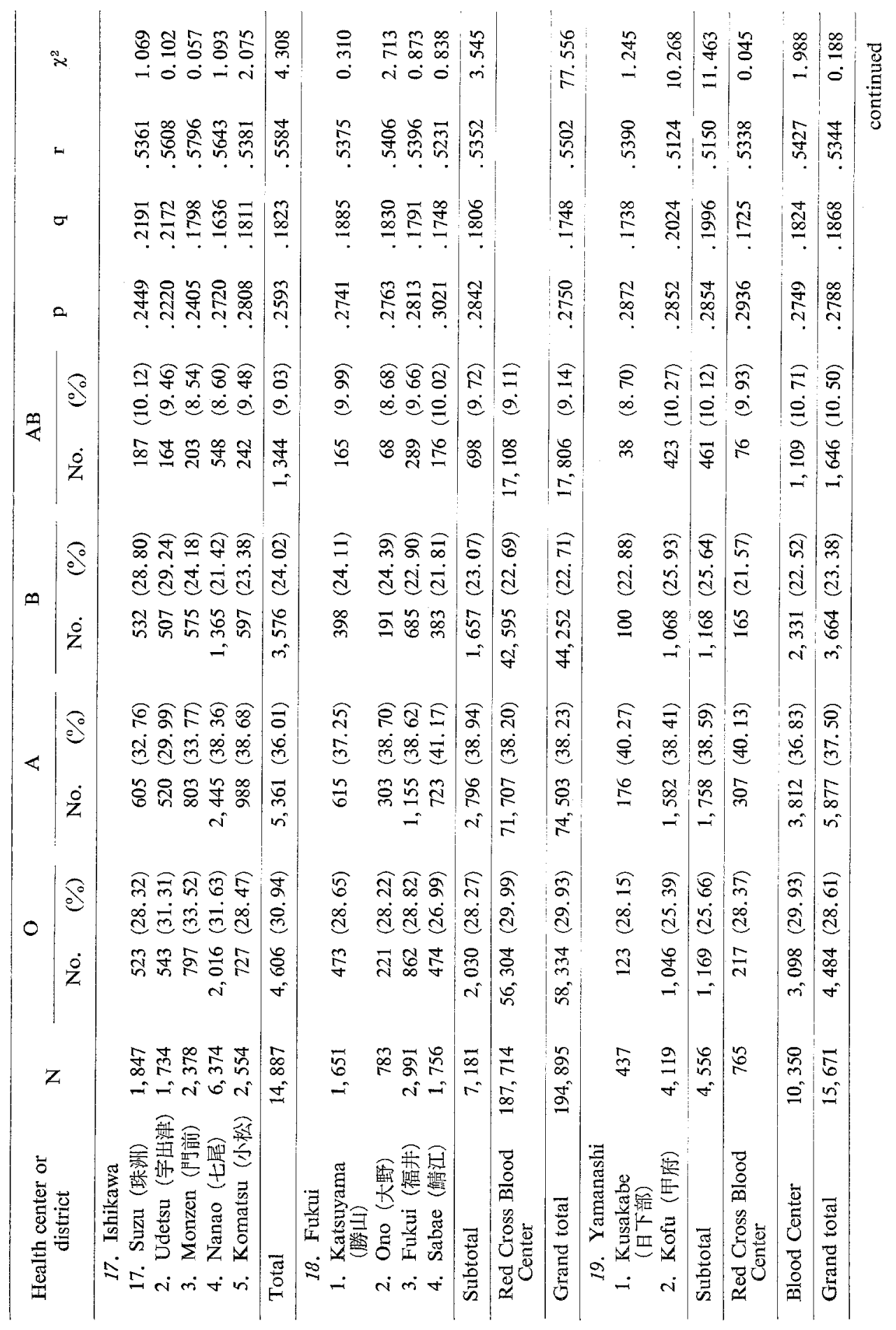




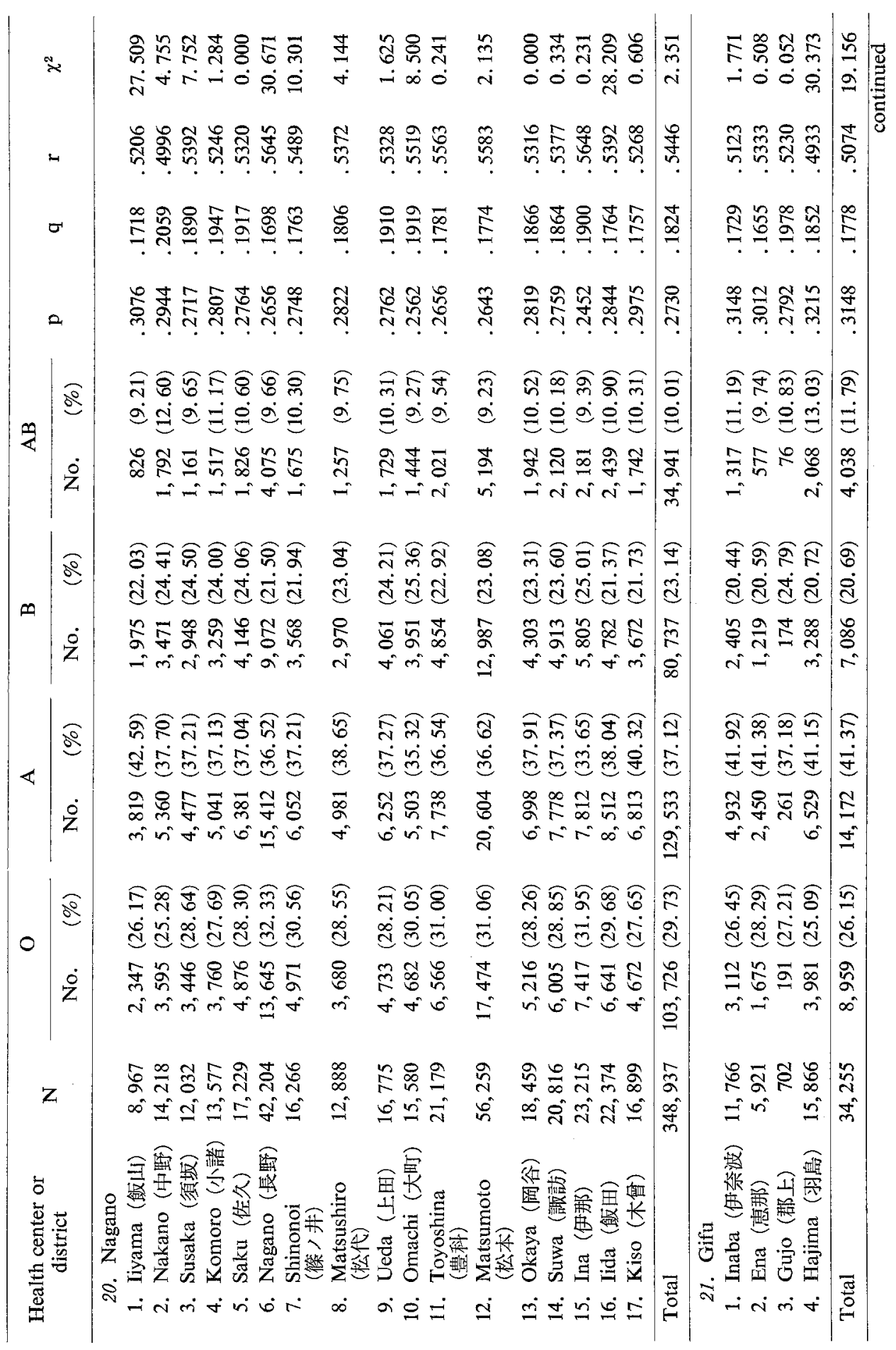




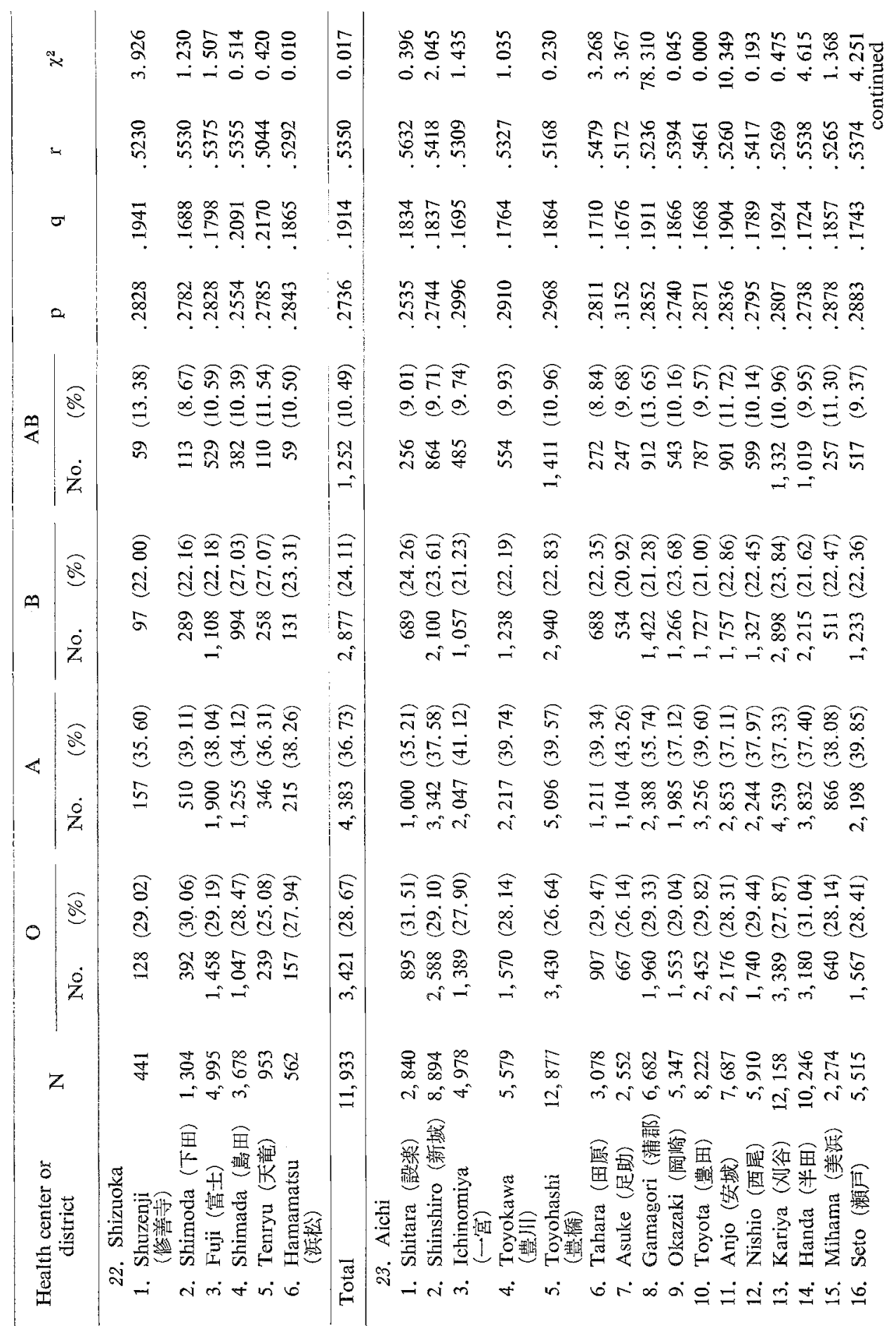




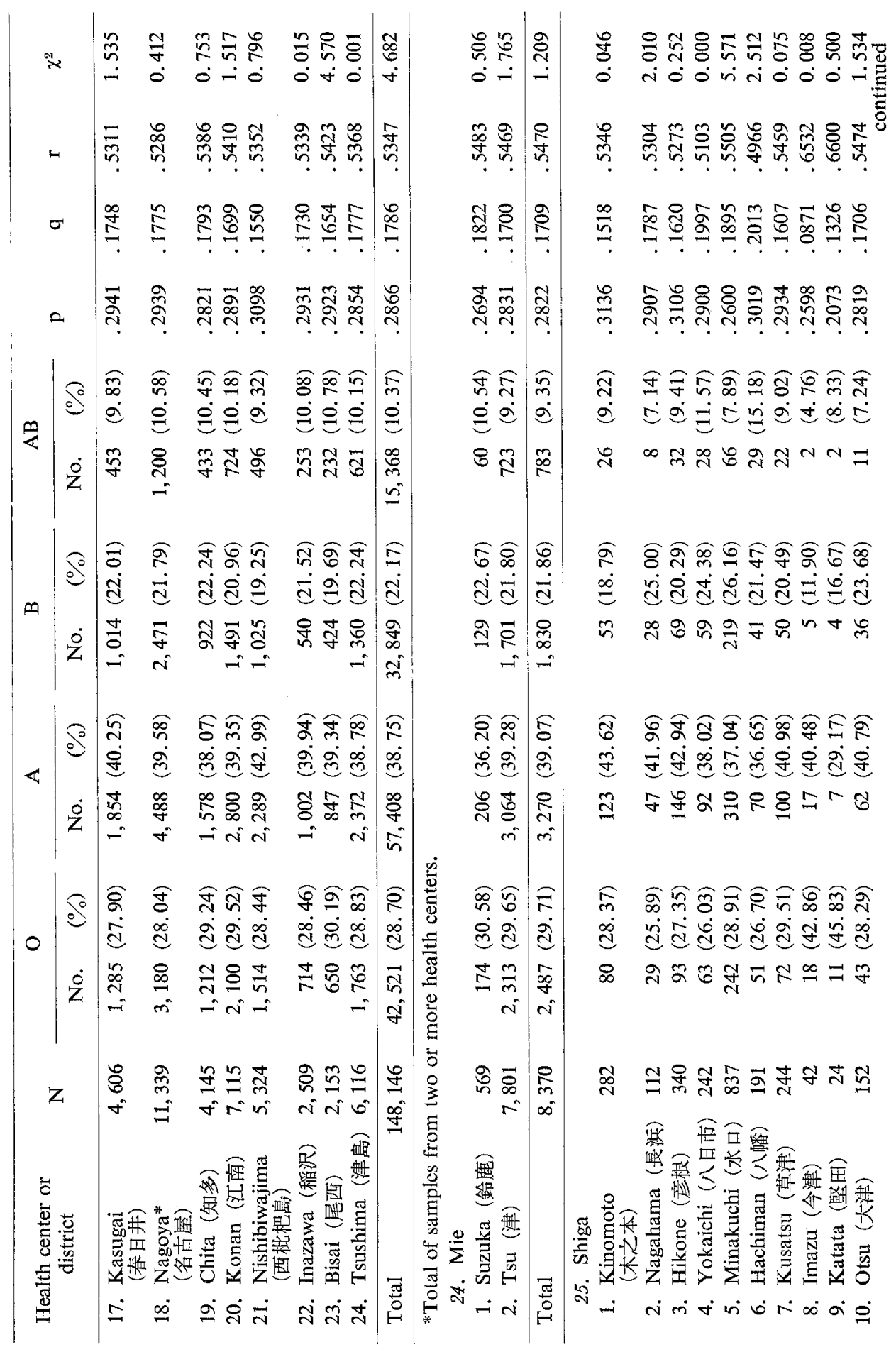




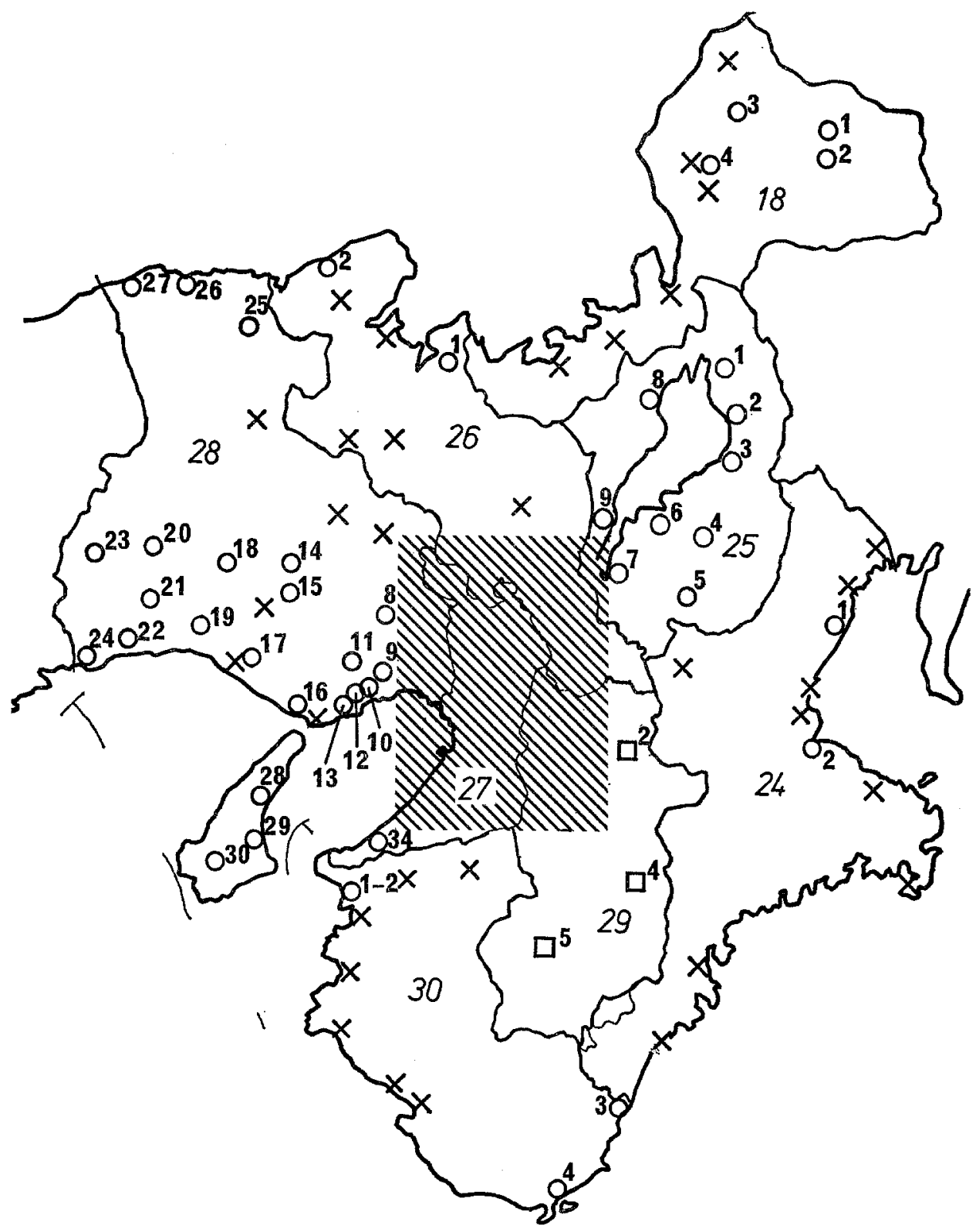

Fig. 11. Kinki District (Prefectures 18 and 24-30). 
ABO BLOOD GROUPS IN JAPAN

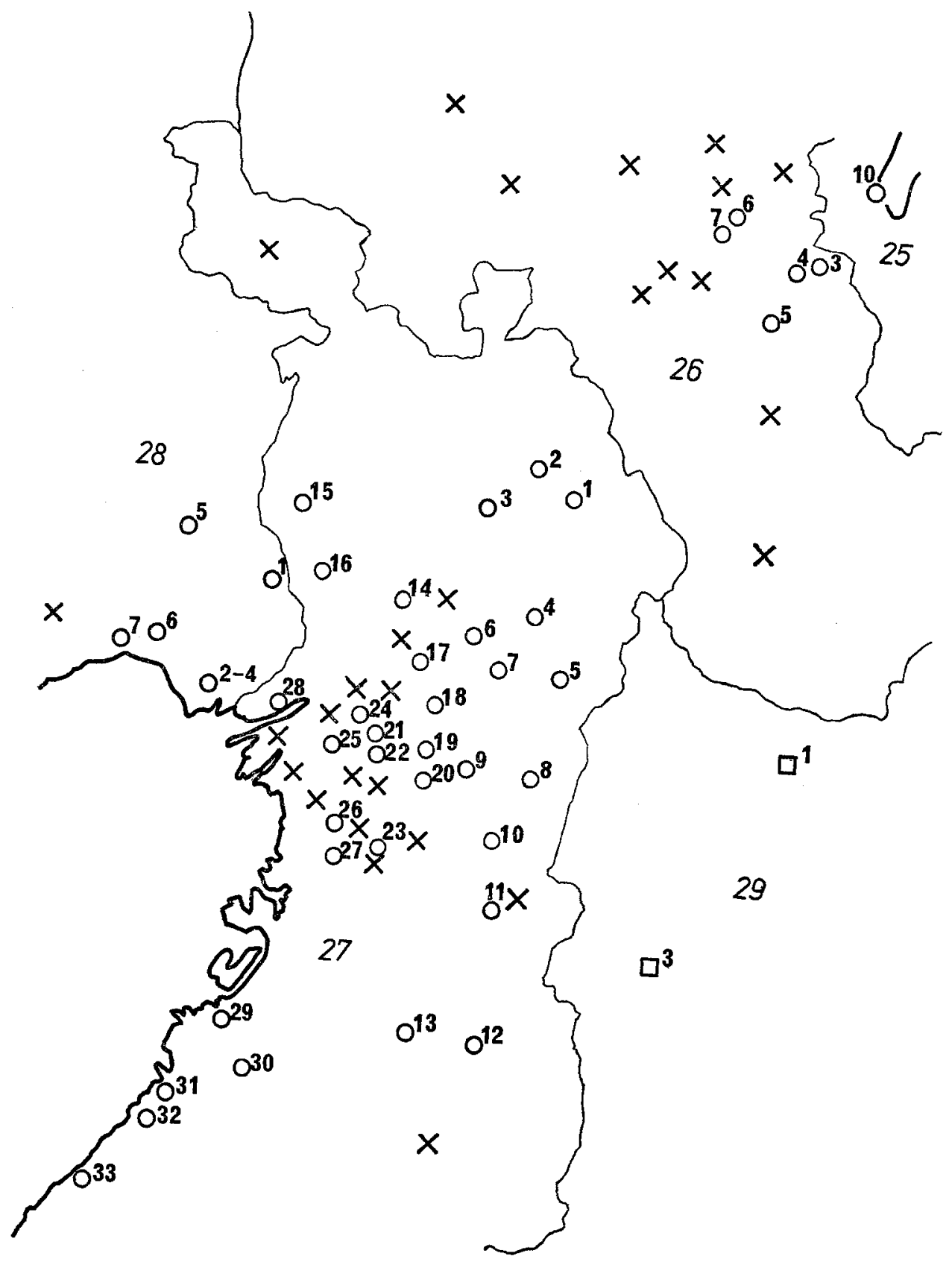

Fig. 12. A part of Kinki District (Osaka and its neighborhood). 


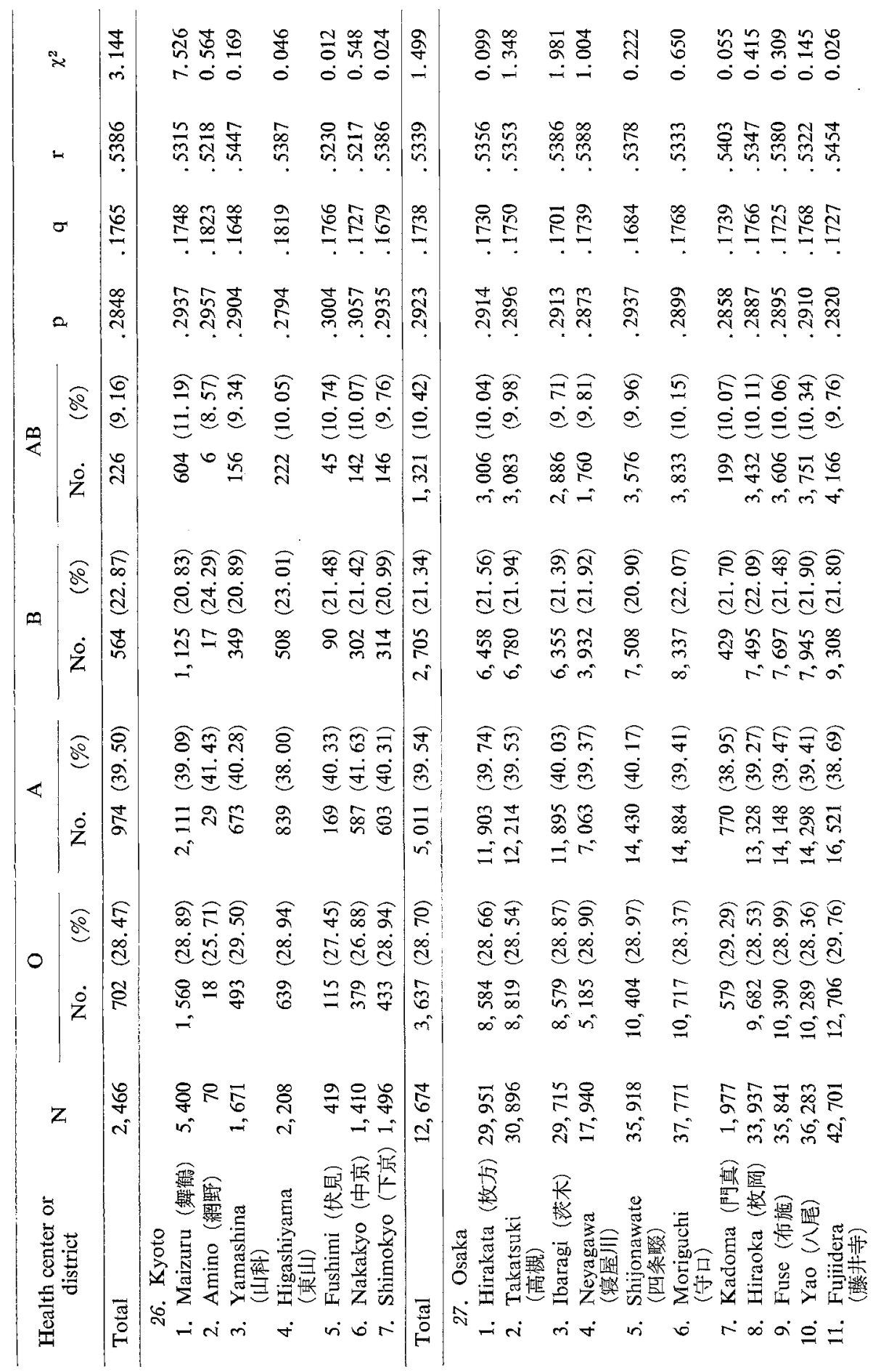




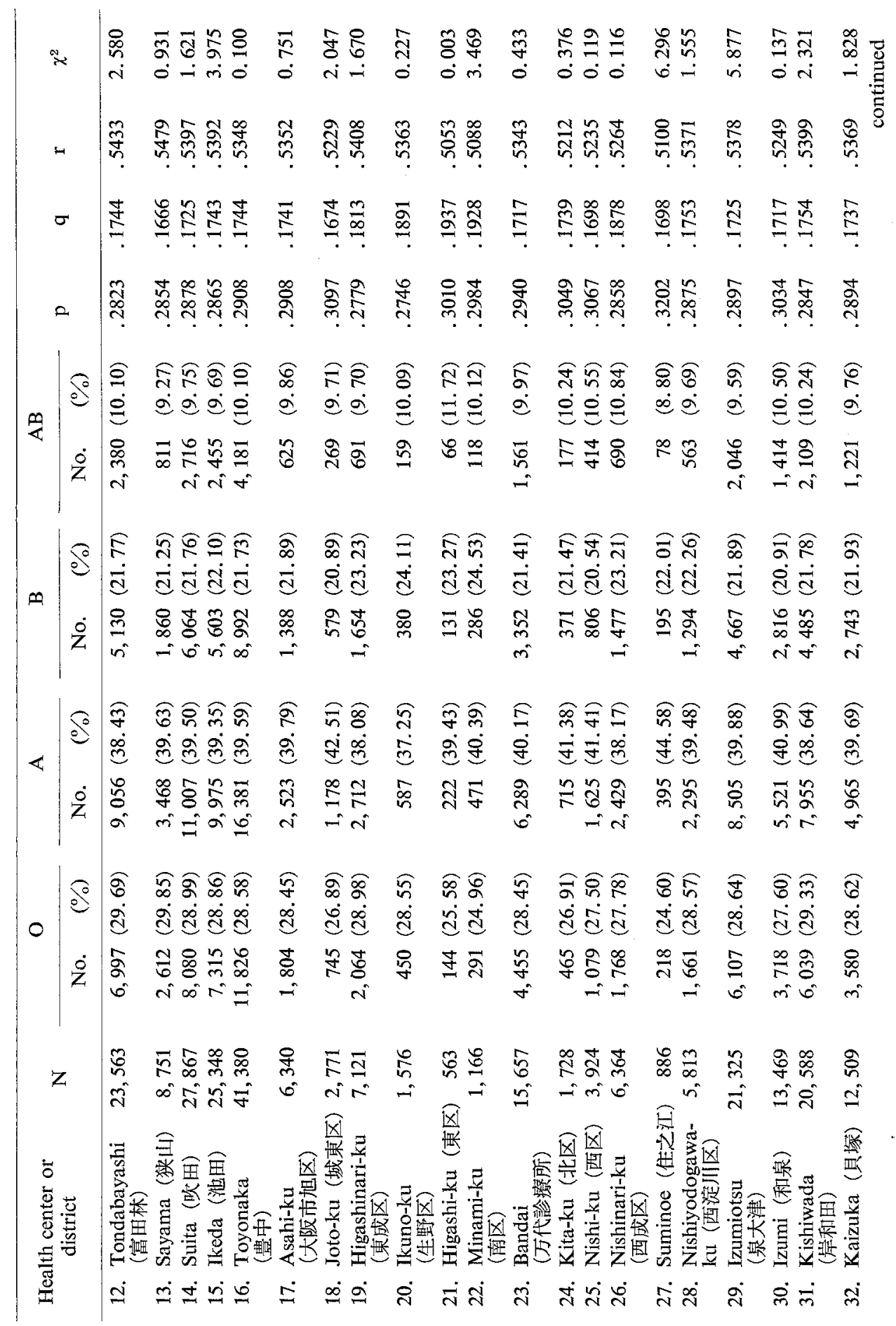




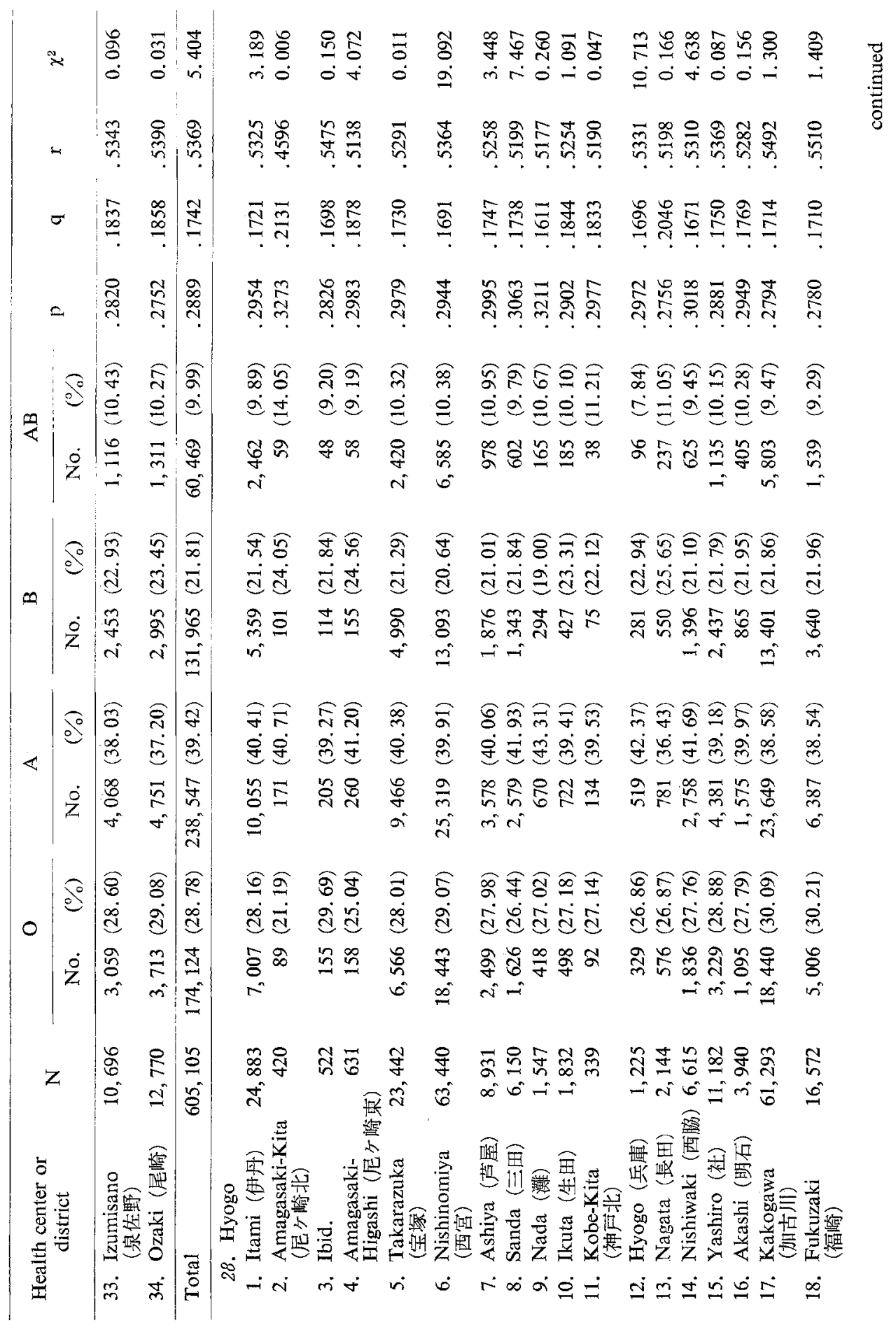




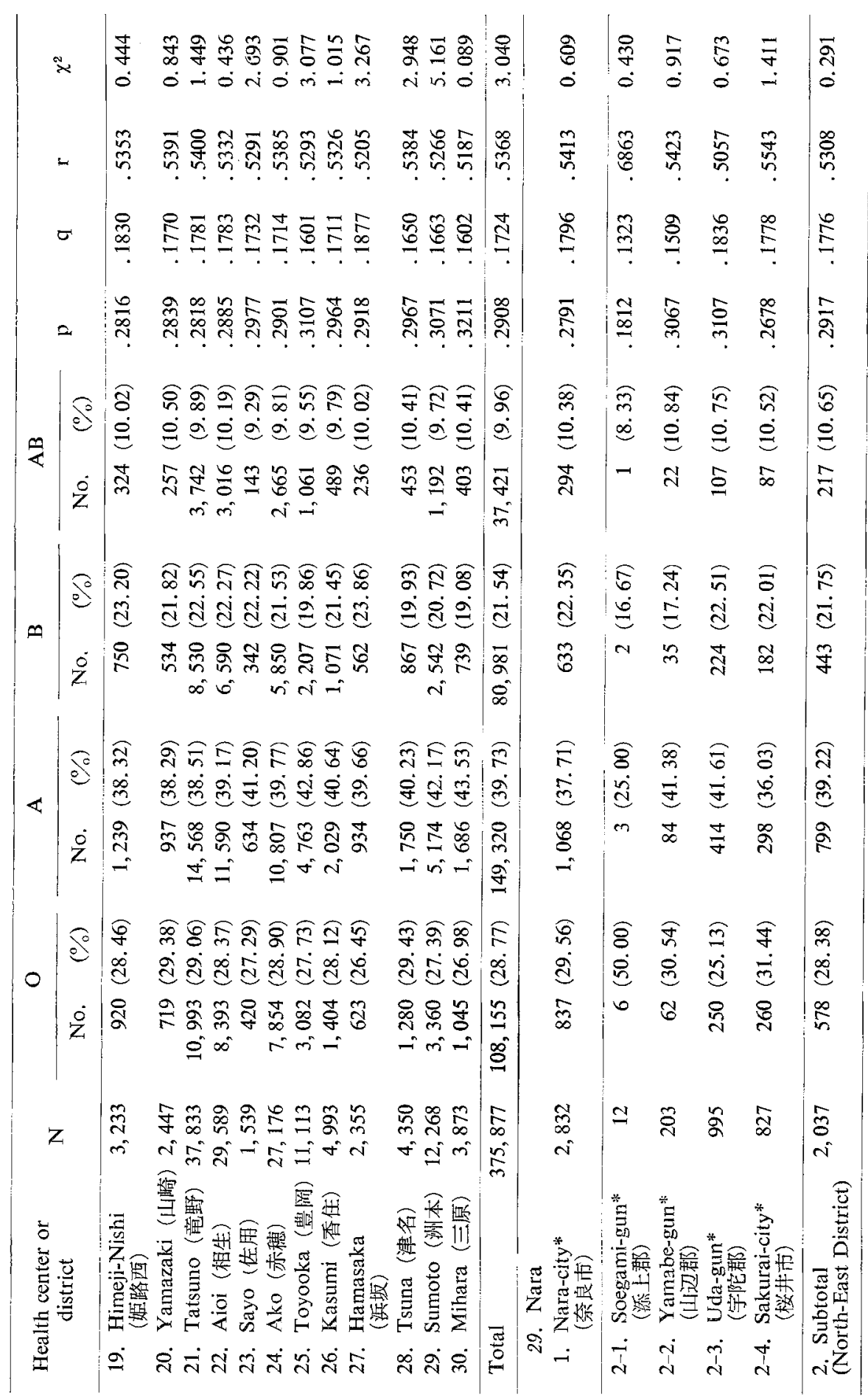




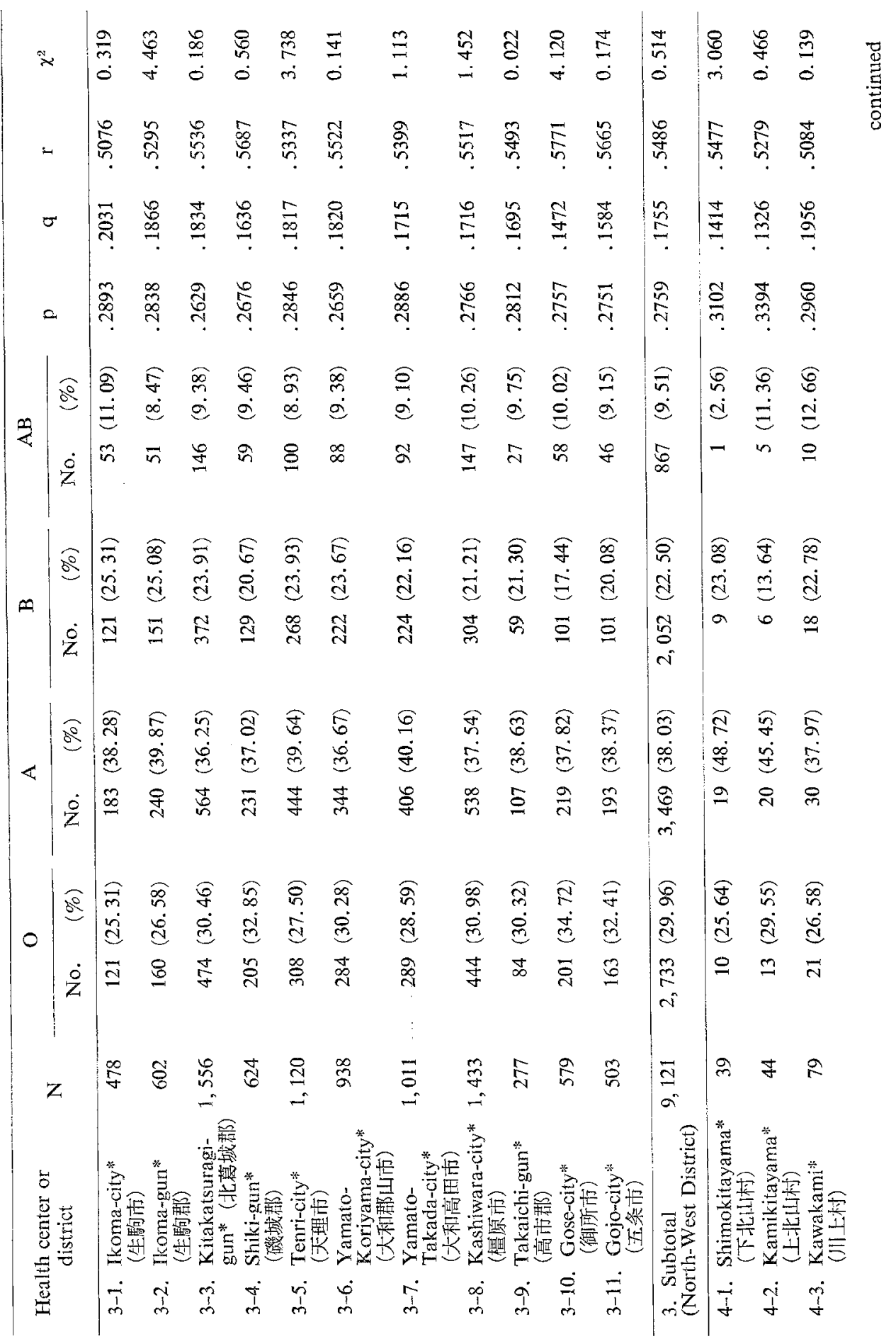




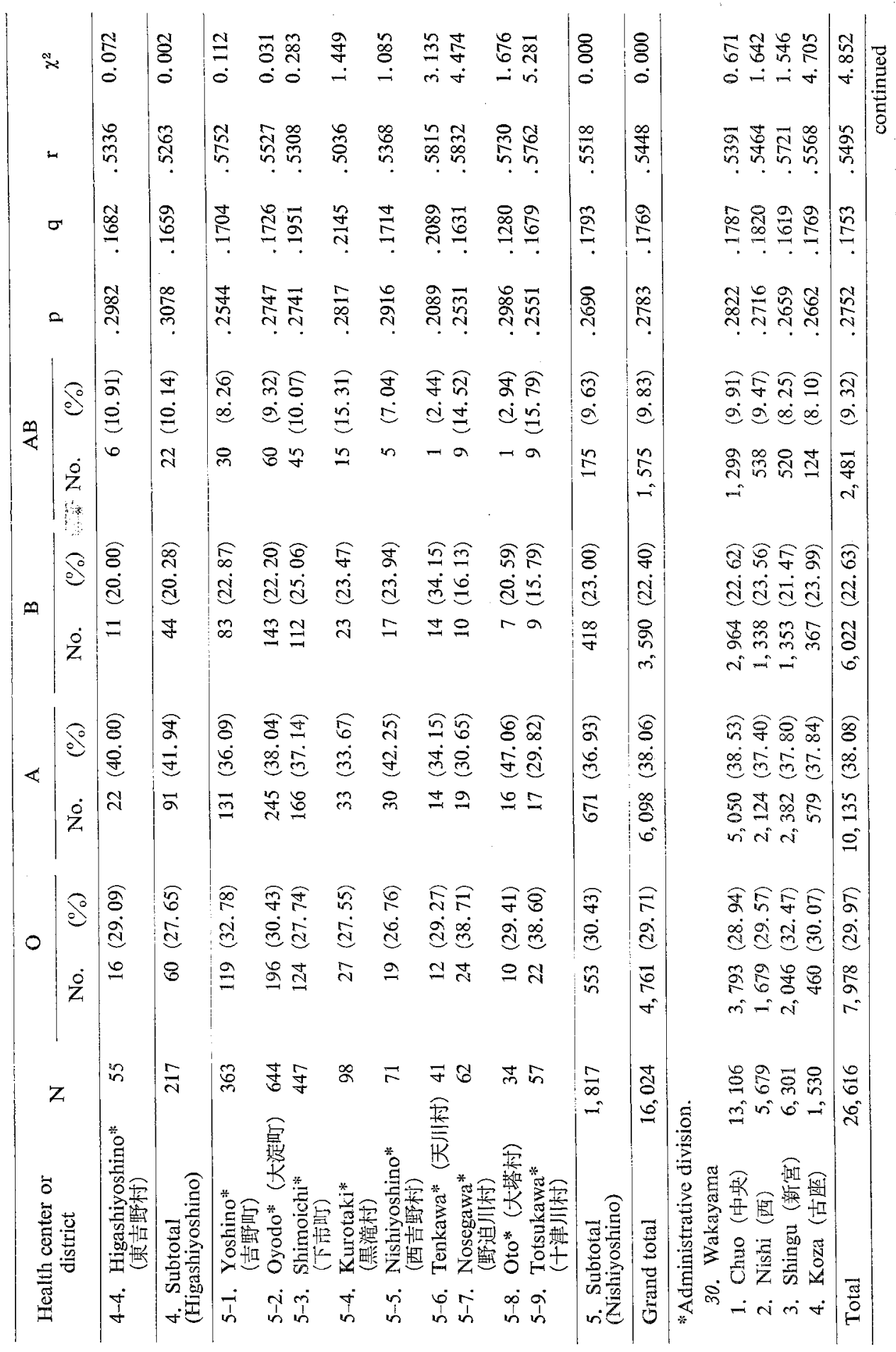




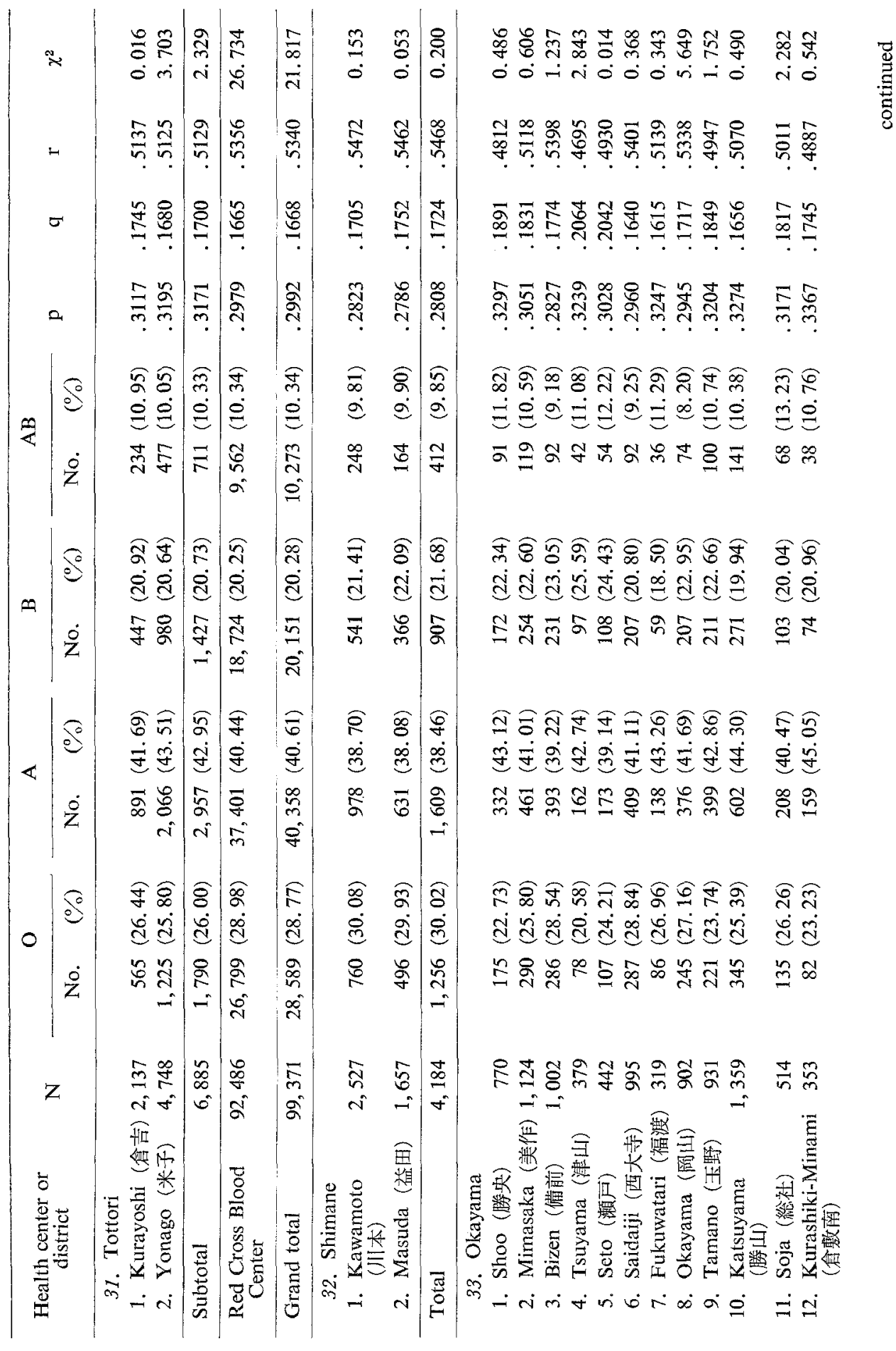




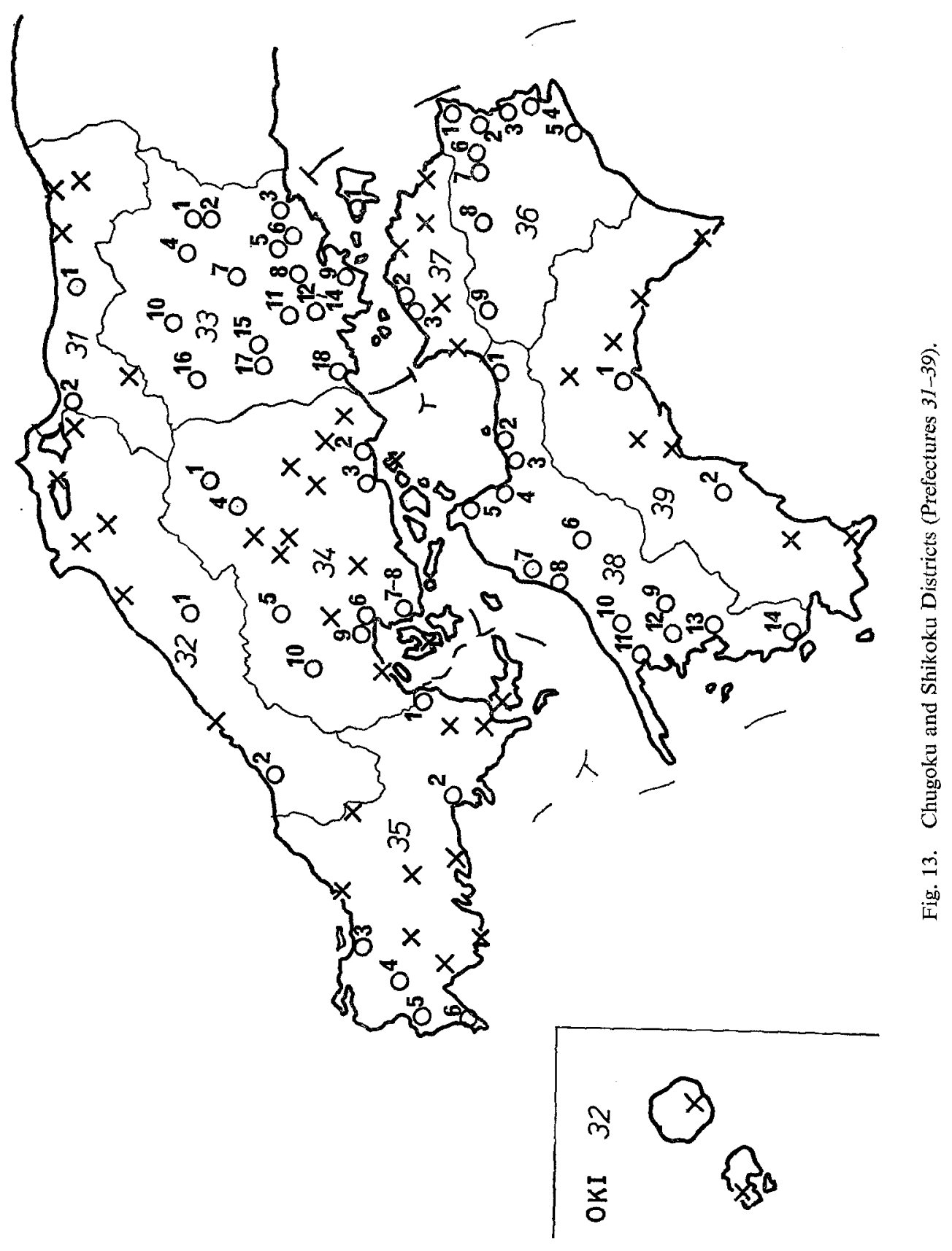




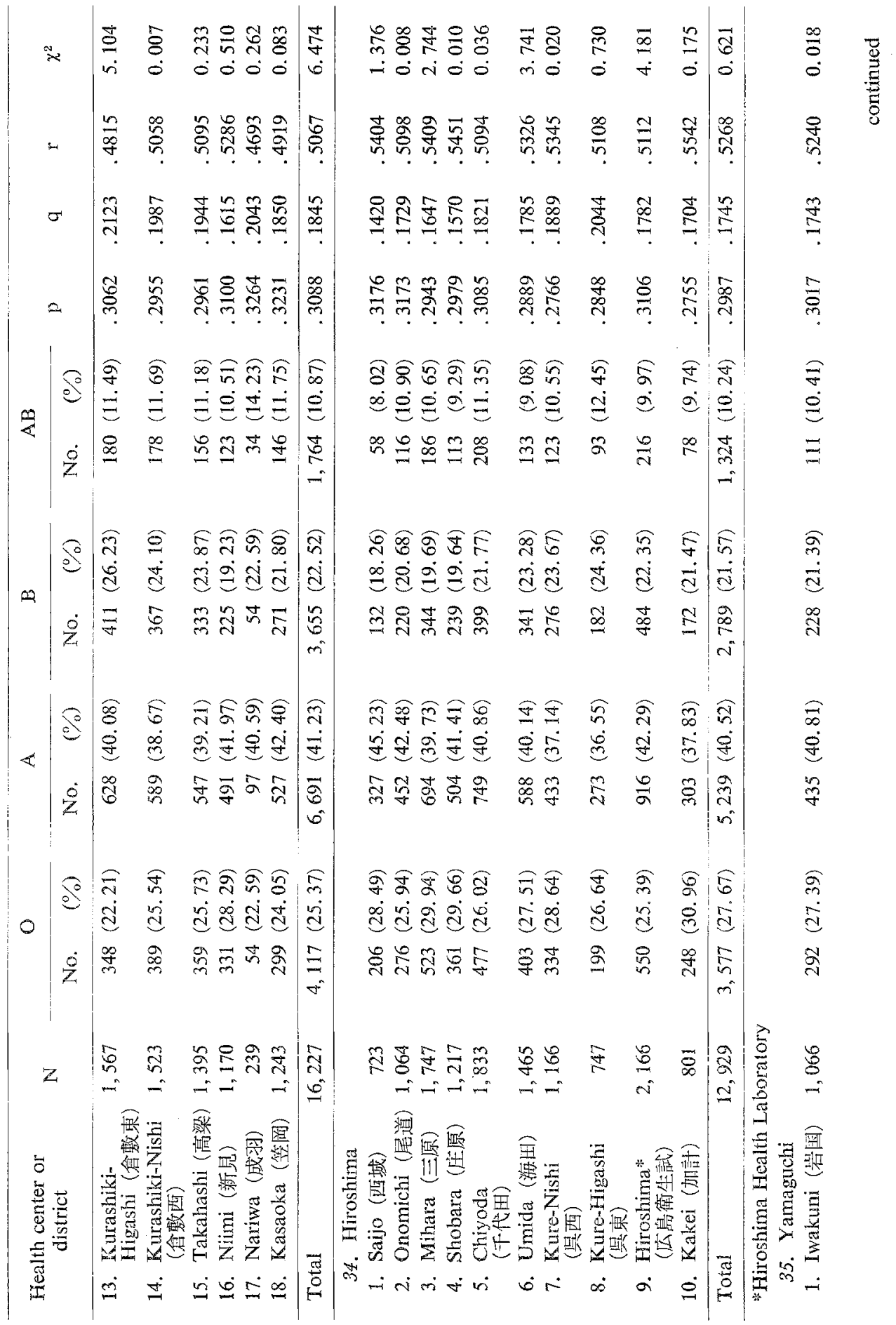




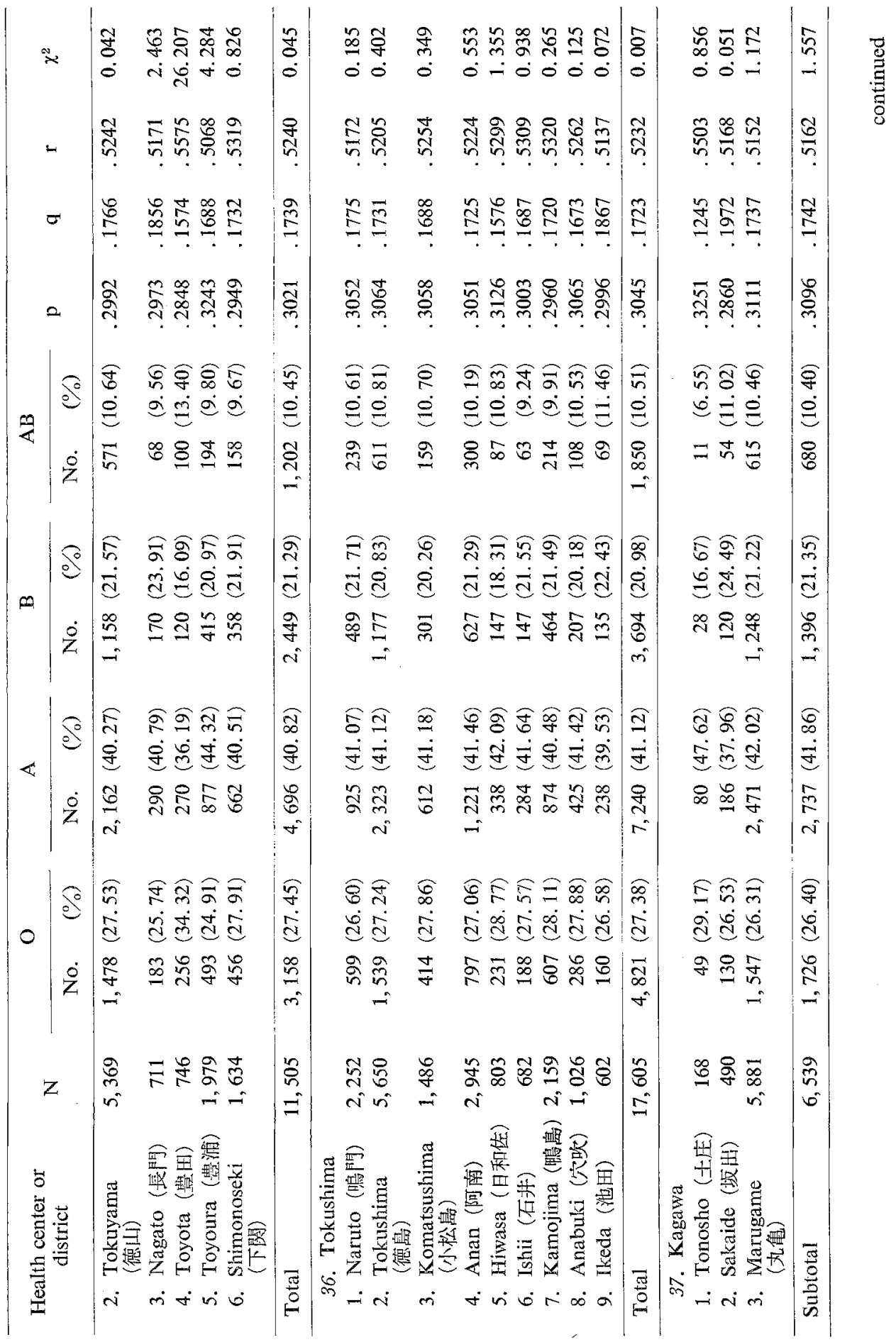




\begin{tabular}{|c|c|c|c|c|c|c|c|c|c|c|c|}
\hline$\approx$ & $\frac{\infty}{2}$ & $\begin{array}{l}\mathscr{q} \\
\dot{y} \\
\dot{i}\end{array}$ & 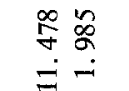 & $\begin{array}{l}9 \\
0 \\
0 \\
0\end{array}$ & 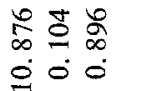 & 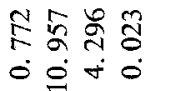 & 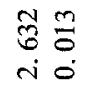 & $\begin{array}{l}8 \\
\ddot{0} \\
\dot{0}\end{array}$ & $\begin{array}{l}E \\
0 \\
0\end{array}$ & 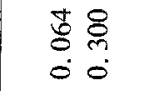 & $\begin{array}{l}F \\
0 \\
0\end{array}$ \\
\hline- & 每 & ণิ & 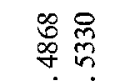 & 离 & 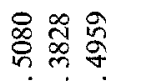 & 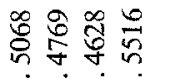 & $8 \frac{2}{5}$ & 鸏 & 㝘 & 岱 & 央 \\
\hline$\sigma$ & $\bar{尺}$ & $\stackrel{0}{\underline{I}}$ & 용 & 点 & 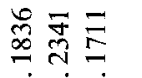 & 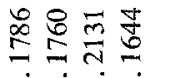 & 88 & $\stackrel{\text { gे }}{\stackrel{\text { g }}{\longrightarrow}}$ & 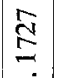 & 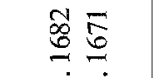 & ? \\
\hline n & 离 & $\overline{\overline{0}}$ & $\frac{\infty}{m} \stackrel{8}{8}$ & 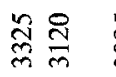 & 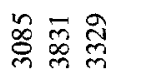 & 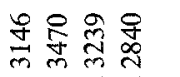 & 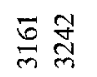 & $\stackrel{\infty}{m}$ & $\underset{N}{\mathbb{N}}$ & 乐 志 & है \\
\hline fo & $E$ & $\widehat{g}$ & 话 & 吉 $\widehat{\not{g}}$ & $\widehat{\nabla} \widehat{\bar{\theta}} \widehat{\otimes}$ & 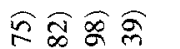 & $\widehat{\infty} \widehat{\infty}$ & สิ & $\widehat{8}$ & 96 & 8 \\
\hline$\infty$ & $\stackrel{0}{\varrho}$ & $\stackrel{\circ}{\varrho}$ & $\dot{m} \dot{\theta}$ & $\dot{\ominus} \equiv$ & $\stackrel{\infty}{=} \dot{\Xi}$ & 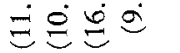 & $\dot{\varrho} \varrho$ & 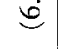 & $\Xi$ & $\Xi \stackrel{\varrho}{巳}$ & $\stackrel{\dot{\theta}}{\Theta}$ \\
\hline$\dot{\mathrm{z}}$ & $\begin{array}{l}n \\
y \\
i\end{array}$ & $\stackrel{\equiv}{m}$ & $\stackrel{\infty}{\infty} \underset{0}{0}$ & 守鱼 & $\hat{n} \tilde{\beta} \%$ & तู่ & 今ั & ले & $\overbrace{0}^{0}$ & तิ & 8 \\
\hline 5 & बू & $\widehat{6}$ & $\widehat{\widehat{\sigma}} \widehat{\infty}$ & 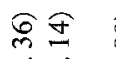 & $\widehat{\alpha} \widehat{\alpha} \hat{b}$ & 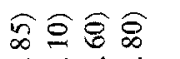 & $\widehat{6} \widehat{6}$ & $\widehat{\Omega}$ & $\widehat{\partial}$ & के & $\widehat{\infty}$ \\
\hline$m$ & $\ddot{I}$ & $\dot{\mathcal{C}}$ & $\dot{\vec{d}} \ddot{\Xi}$ & $\stackrel{\infty}{=} \stackrel{\infty}{=}$ & $\dot{d} \stackrel{\vec{d}}{0}$ & ¿். & $\dot{\bar{c}} \stackrel{\infty}{=}$ & $\stackrel{2}{E}$ & $\dot{\mathrm{d}}$ & $E$ & $\stackrel{\circ}{=}$ \\
\hline$\dot{z}$ & $\begin{array}{l}0 \\
6 \\
\forall \\
\forall\end{array}$ & $\begin{array}{l}8 \\
8 \\
0\end{array}$ & $\stackrel{m}{a} \bar{g}$ & 弚 宗 & & 흠용 & 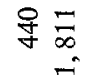 & $\stackrel{0}{0}$ & הి & $\widehat{\widehat{\sigma}} \widetilde{\sigma}$ & $\hat{\infty}$ \\
\hline so & $\widehat{a}$ & ठิ & $E \odot$ & $\widehat{N} \widehat{F}$ & $\widehat{F} \widehat{\infty} \widehat{\infty}$ & 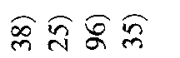 & E尺矛 & $\widehat{\approx}$ & ลू & $\hat{D} \hat{\overline{1}}$ & I \\
\hline$\varangle$ & $\dot{\Xi}$ & $\dot{\Xi}$ & $\dot{q} \dot{9}$ & 离守 & 至导守 & 过过官 & 过过 & 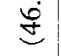 & $\stackrel{y}{y}$ & $\dot{\vec{g}} \dot{g}$ & $\stackrel{p}{g}$ \\
\hline$\dot{0}$ & $\stackrel{\Re}{\sim}$ & $\stackrel{1}{0}$ & రి & :ొర & 织萬品 & 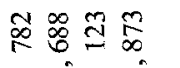 & 묘요 & $\widetilde{\sigma}$ & $\begin{array}{l}n \\
\infty \\
n\end{array}$ & $\tilde{2}$ & 8 \\
\hline & $a^{\circ}$ & $\simeq$ & i & & 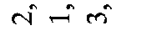 & & & $N$ & 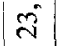 & $N=$ & $\nabla^{n}$ \\
\hline ริ & $\widehat{\infty}$ & $\hat{n}$ & $\widehat{\widehat{n}} \widehat{\bar{a}}$ & สิล & \& & 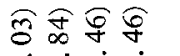 & $\widehat{\delta} \bar{\sigma}$ & 鬲 & in & वิ & $\pi$ \\
\hline 0 & $\bar{d}$ & 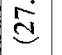 & $\stackrel{d}{d} \stackrel{0}{d}$ & $\stackrel{\infty}{d}$ & $\stackrel{d}{d}$ & $\stackrel{d}{\mathbb{d}} \ddot{d}$ & $\ddot{d}$ & $\bar{\Xi}$ & $\stackrel{a}{d}$ & $\stackrel{d}{d}$ & $\ddot{a}$ \\
\hline$\dot{0}$ & $\mid$\begin{tabular}{l}
\multirow{2}{*}{} \\
6 \\
6
\end{tabular} & $\begin{array}{l}\stackrel{8}{8} \\
\infty \\
\infty\end{array}$ & 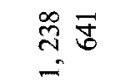 & 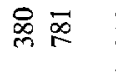 & 怘岕点 & 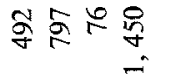 & 象完 & $\underset{\sim}{\tilde{Z}}$ & ڤ & $\tilde{\Omega}$ & 8 \\
\hline z & $\begin{array}{l}\frac{\hat{\sigma}}{2} \\
\hat{\text { vे }}\end{array}$ & $\begin{array}{l}\infty \\
2 \\
2 \\
2\end{array}$ & $\begin{array}{l}\infty \tilde{y} \\
\dot{0} \vec{n} \\
\dot{n} \tilde{n}\end{array}$ & $\begin{array}{l}\frac{g}{\bar{g}} \bar{R} \\
-i i\end{array}$ & 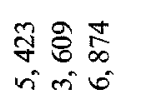 & 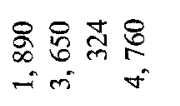 & $\begin{array}{l}m \\
\text { ma } \\
\text { i }\end{array}$ & $\begin{array}{l}8 \\
\text { in } \\
\text { n }\end{array}$ & $\begin{array}{l}0 \\
2 \\
\infty \\
i \\
5\end{array}$ & 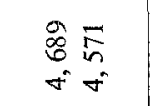 & 总 \\
\hline 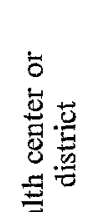 & 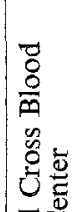 & 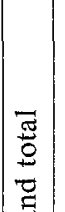 & 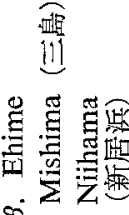 & 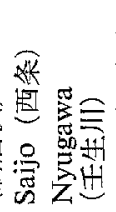 & 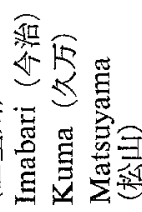 & 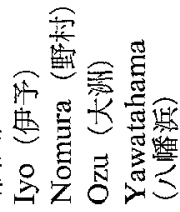 & 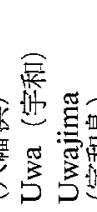 & 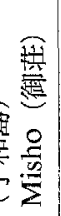 & & 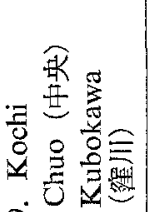 & 要 \\
\hline 苾 & 总 & $\vec{E}$ & $m-i$ & $\dot{m} \dot{r}$ & in 0 & $\infty \dot{\sigma} \dot{\theta}=$ & $\stackrel{i m}{=}$ & $\dot{\square}$ & 要 & & 营 \\
\hline
\end{tabular}




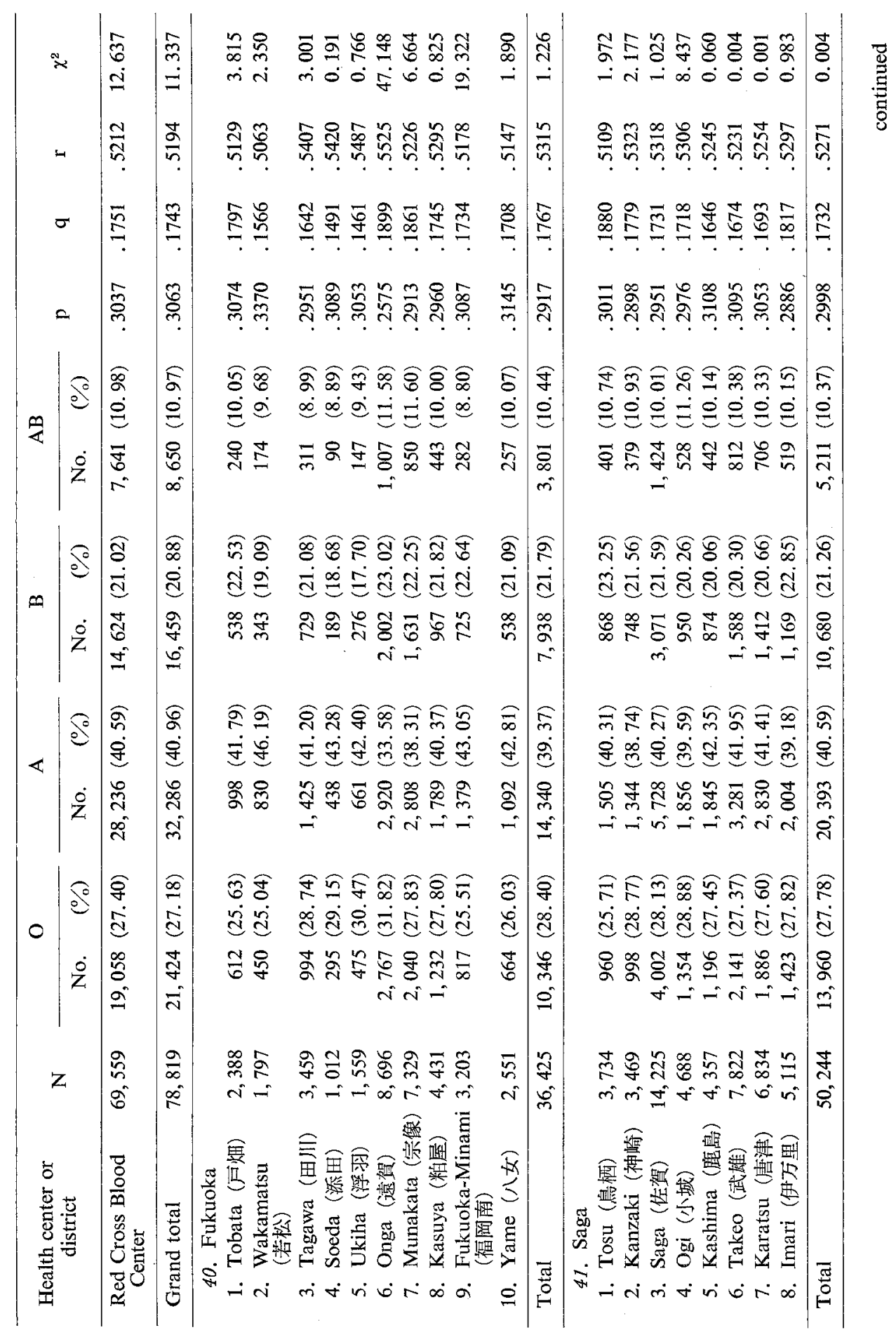




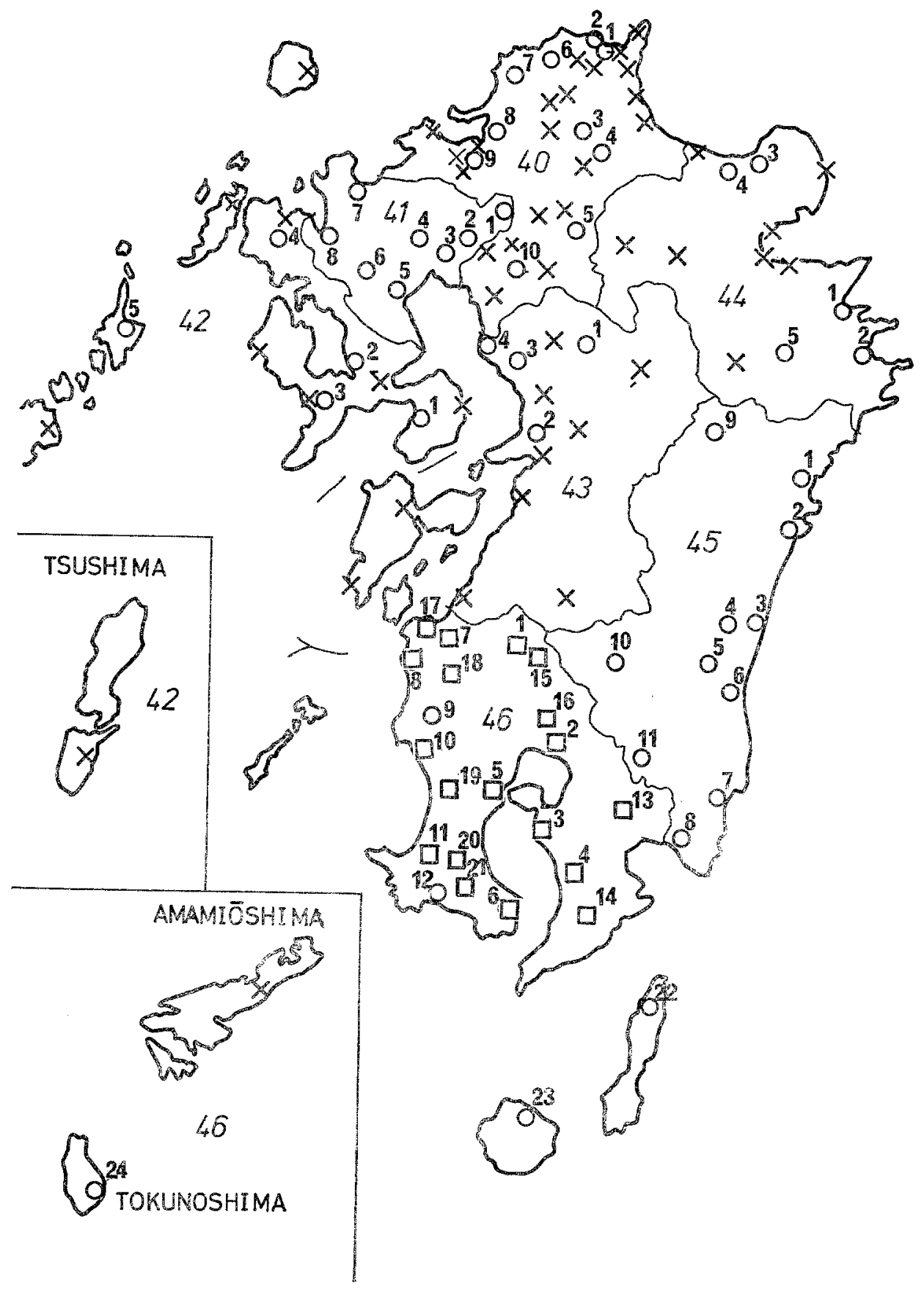

Fig. 14. Kyushu District (Frefectures 40-40). 


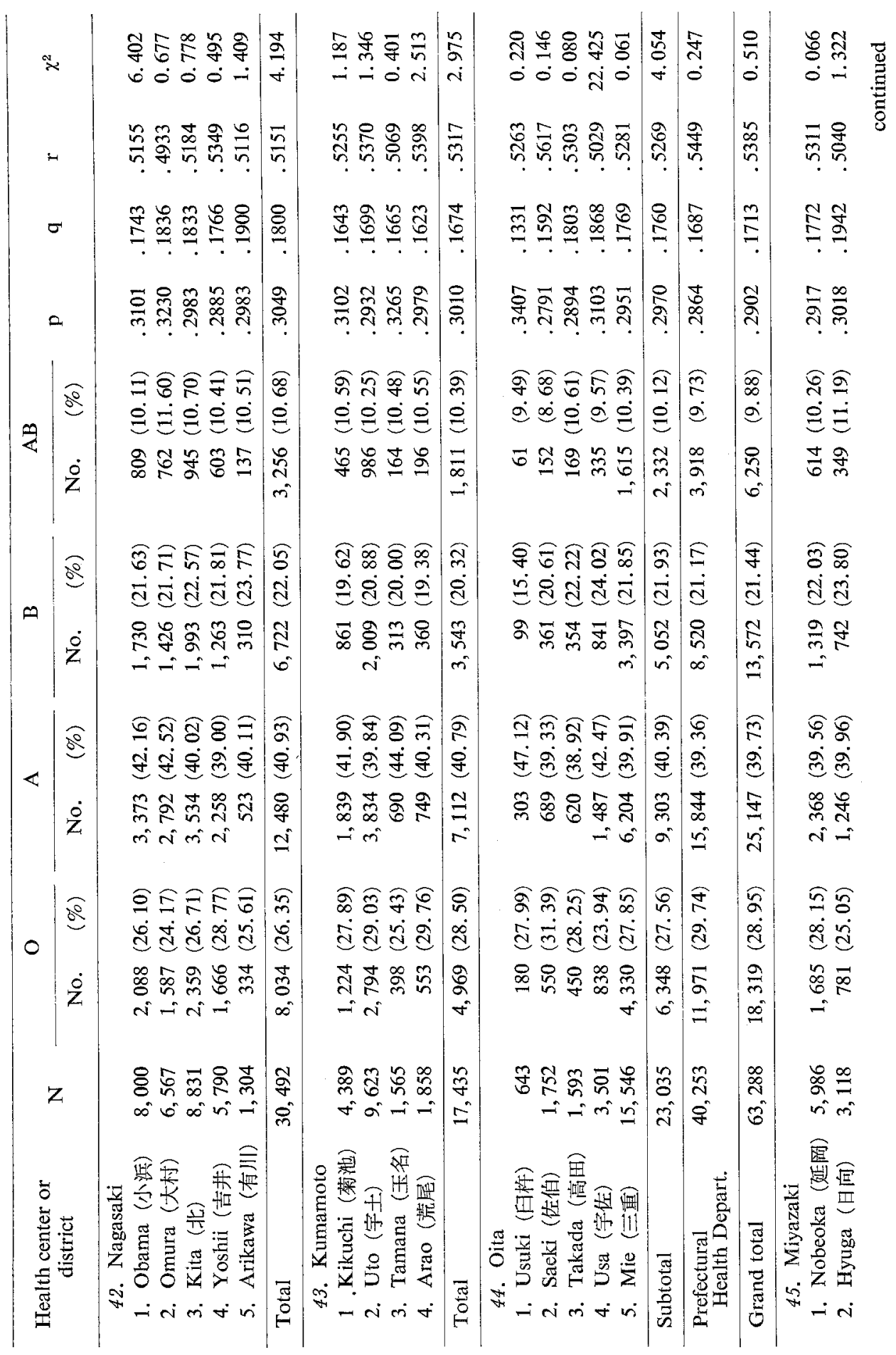




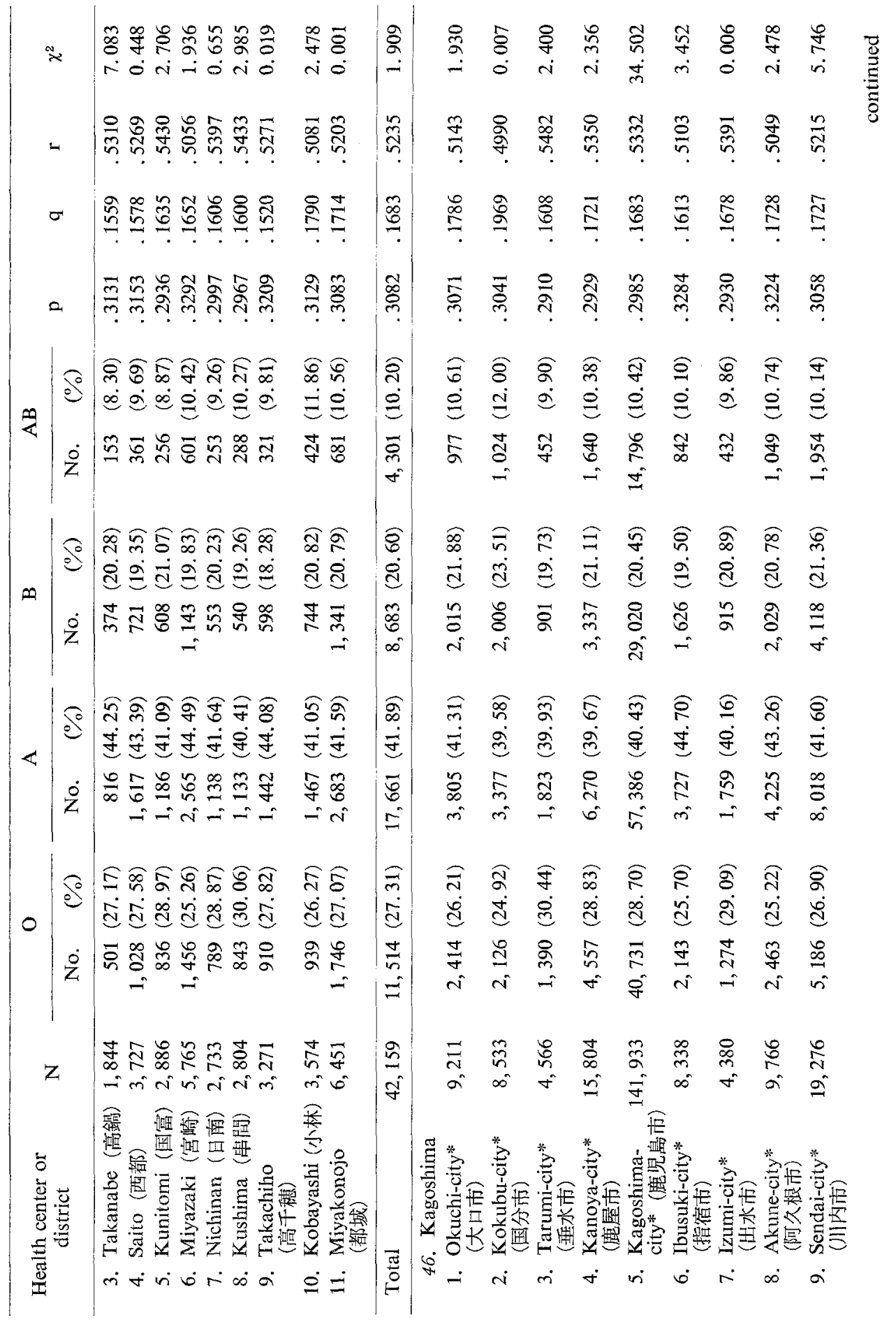




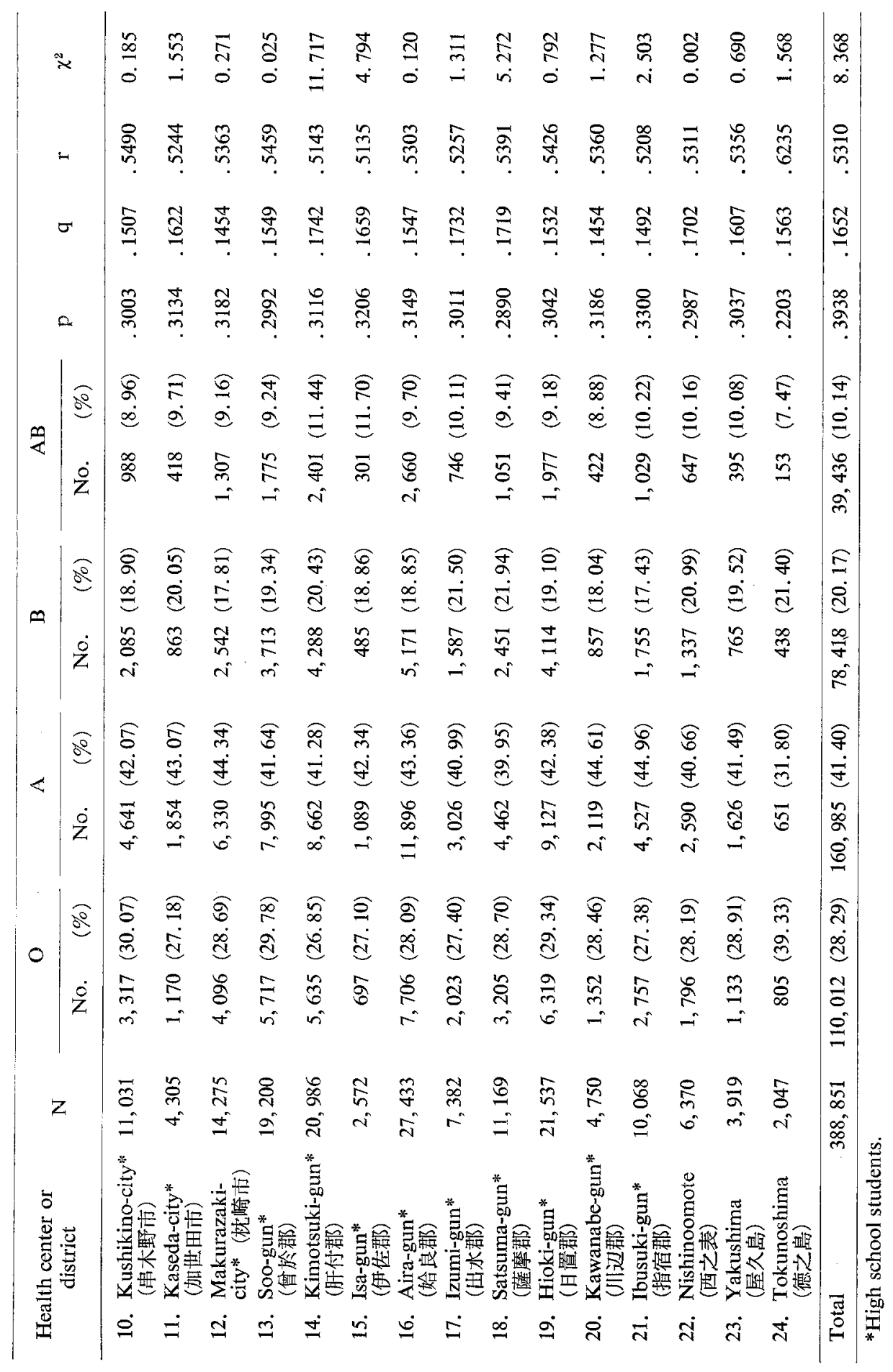

